\title{
Automated Processing for Flood Area Detection Using ALOS-2 and Hydrodynamic Simulation Data
}

\author{
Masato Ohki ${ }^{1, * \mathbb{C}}$, Kosuke Yamamoto ${ }^{1}$, Takeo Tadono ${ }^{1}\left[{ }^{\mathbb{D}}\right.$ and Kei Yoshimura ${ }^{1,2}$ \\ 1 Earth Observation Research Center, Japan Aerospace Exploration Agency, 2-1-1 Sengen, Tsukuba, \\ Ibaraki 305-8505, Japan; yamamoto.kosuke@jaxa.jp (K.Y.); tadono.takeo@jaxa.jp (T.T.); \\ kei@iis.u-tokyo.ac.jp (K.Y.) \\ 2 Institute of Industrial Science, The University of Tokyo, 5-1-5 Kashiwanoha, Kashiwa, Chiba 277-8574, Japan \\ * Correspondence: ohki.masato@jaxa.jp
}

Received: 6 July 2020; Accepted: 19 August 2020; Published: 21 August 2020

\begin{abstract}
Rapid and frequent mapping of flood areas are essential for monitoring and mitigating flood disasters. The Advanced Land Observing Satellite-2 (ALOS-2) carries an L-band synthetic aperture radar (SAR) capable of rapid and frequent disaster observations. In this study, we developed a fully automatic, fast computation, and robust method for detecting flood areas using ALOS-2 and hydrodynamic flood simulation data. This study is the first attempt to combine flood simulation data from the Today's Earth system (TE) with SAR-based disaster mapping. We used Bayesian inference to combine the amplitude/coherence data by ALOS-2 and the flood fraction data by TE. Our experimental results used 12 flood observation sets of data from Japan and had high accuracy and robustness for use under various ALOS-2 observation conditions. Flood simulation contributed to improving the accuracy of flood detection and reducing computation time. Based on these findings, we also assessed the operability of our method and found that the combination of ALOS-2 and TE data with our analysis method was capable of daily flood monitoring.
\end{abstract}

Keywords: synthetic aperture radar; radar interferometry; disaster monitoring; PALSAR-2; flood model

\section{Introduction}

Flooding is the most frequent and widespread natural disaster, which has affected more than 800,000 people and caused USD 300 billion in economic losses over the past decade [1]. In Japan, for example, approximately $41 \%$ of the population and $65 \%$ of national assets are concentrated in flood-prone areas [2]. Global climate change and rapid urbanization are expected to further increase the risk of flooding in the future [3]. Accurate and rapid mapping of the extent of flooding is, thus, essential for disaster management and mitigation, such as providing search and rescue services and floodwater drainage.

Remote sensing technology, particularly synthetic aperture radar (SAR), has long been expected to play an important role in rapid flood monitoring because of its ability to make observations in any weather, day or night [4]. Over the past two decades, many SAR satellites have been launched, creating a constellation of satellites that provide frequent quasi-real-time observation of floods in high resolution. The Advanced Land Observing Satellite-2 (ALOS-2) carries an L-band SAR, the Phased Array-type L-band Synthetic Aperture Radar-2 (PALSAR-2), for monitoring disasters and environmental changes [5]. ALOS-2 is characterized by the unique local solar time (LST) of its observations (at 0:00 and 12:00), which cover hours not monitored by other SAR satellites observing at 6:00 and 18:00 LST (such as TerraSAR-X, COSMO-SkyMed, RADARSAT-2, and Sentinel-1). Observations at 0:00 LST are particularly important because optical remote sensing and ground surveys cannot be performed at 
midnight. ALOS-2 also has the flexibility to change observation off-nadir angles and left- and right-looking for quick access to an affected area. Given these benefits, we need to understand quantitatively the effectiveness of ALOS-2 for rapid flood mapping.

SAR-based flood mapping needs to consider several types of land cover with different radar backscattering characteristics: (i) open-water flooding, where bare soil and sparse vegetation are completely submerged; (ii) flooding of built-up areas, where buildings and other high structures are flooded but where the upper parts of the structures remain above water; (iii) flooding of vegetation areas.

(i) Detecting open-water flooding has been extensively investigated, particularly using SARs with shorter wavelengths such as X- and C-bands [6-9]. Basically, strong specular reflection (low backscattering) from the smooth surface of floodwater appears as dark areas in a SAR amplitude image. However, L-band, a longer wavelength used by ALOS-2, is relatively ineffective at detecting open-water flooding; the backscattering is less indicative of the roughness of bare soil and sparse vegetation, particularly at large incidence angles (approximately $>40^{\circ}$ ) [10].

(ii) Flooding of built-up areas cannot be detected in the same way as (i) because of the strong backscattering from buildings. Detecting the increase in amplitude caused by the double-bounce effect may be feasible but it is not a reliable method because it depends on the orientation angle of buildings [11,12]. Instead, the coherence that can be obtained from interferometric SAR (InSAR) processing is effective for detecting affected buildings, regardless of their orientation [10,13-15]. The problem with coherence is that it varies not only with the location of the incident but also with factors such as the temporal distance of the interferometric pair. Ideally, a pair of data with a brief time interval (e.g., one day) and identical observation conditions should be used for InSAR to minimize these errors. However, in actual satellite operations, we are often forced to use data with different observation modes and with long temporal intervals (i.e., $>1$ year). Therefore, we must develop a robust method that is less sensitive to these factors.

(iii) Flooding of areas with partially submerged vegetation can be detected using the double-bounce effect caused by the horizontal surface of water and vertical tree trunks [16,17].

Fast and automatic processing is needed to monitor flooding by SAR. Manual operation and interpretation during a disaster are difficult and time-consuming. Previous research has addressed fully automated algorithms based on a split-image approach [18,19], a multi-temporal and multi-incidence angle data model [20], and machine learning [21-23]. Some of these ideas have already been implemented in automatic processing chains using X-and C-band SAR data [24,25], but the use of L-band remains a challenge because it is less sensitive to floods. Furthermore, complex methods, especially those using machine learning, and semi-automatic methods that require manual operation or interpretation are time consuming and not suitable for our goal. The disaster response community in Japan wants a latency of fewer than two hours for processing [26]. Considering the time for data downlink from the satellite and standard processing (SAR imaging, calibration, etc.), the flood detection process should be done within $30 \mathrm{~min}$.

To fulfill these requirements, we developed a fully automatic, fast processing, and robust method that can be used with non-ideal observation conditions such as a wide range of off-nadir angles. The present study targeted flooding in urban areas in Japan where vegetation flooding (iii) was rare; thus, the present method takes into account (i) open-water and (ii) built-up flooding.

Combining remote sensing data with other tools such as hydrodynamic models is a promising approach for better monitoring of floods. We used complementary SAR data by ALOS-2 and flood simulation data by the Today's Earth system (TE) [27]. TE provides physical quantities regarding flood and water cycles based on hydrodynamic models, using meteorological reanalysis and observation datasets [28,29]. The probabilistic models based on Bayesian networks were reported to show good capability for flood detection using SAR (amplitude and coherence) and flood simulation data [30]. However, the previous approaches require many classification categories, complex probability density functions (e.g., a K-means clustering model), and human decisions to interpret results, all of which are time-consuming processes that cannot be directly applied to our goal. For the robustness and 
computational efficiency of the algorithm, we employed a Bayesian inference assuming simple Gaussian distributions of SAR data [31] and combined flood fraction data by TE as prior probabilities of flooding.

Our method generates polygonised (vector) data as a final product because they are easy to understand by end-users (non-specialists in remote sensing) working for on-site disaster response. Furthermore, polygon data have a much smaller file size than image data and can easily be sent to and managed by geographical information systems (GIS).

To validate the accuracy and robustness of our method, we processed 12 datasets for urban-area flooding in Japan acquired by ALOS-2 under a variety of observation conditions. The previous research studies on flood detection by ALOS-2 were case studies that analyzed a few flood events that were insufficient for a feasibility study. Furthermore, we provisionally implemented our method within the ALOS-2 ground processing system and measured computational speed to evaluate its suitability for operational use.

\section{Datasets}

\subsection{SAR Data by ALOS-2}

We tested our method with 12 sets of ALOS-2 data corresponding to seven flood events in Japan, as listed in Table 1: flooding in Joso, Ibaraki Prefecture (cases 1 to 5) caused by the heavy rainfall in the Kanto-Tohoku area in September 2015 [32]; flooding in Kitami, Hokkaido Pref. (case 6) by Typhoon Mindulle in August 2016 [33]; flooding in Mabi, Kurashiki city, Okayama Pref. (case 7) by Typhoon Prapiroon in July 2018 [34]; flooding in Saga Pref. (cases 8 and 9) by a stationary front in August 2019 [35]; flooding in Chikuma, Nagano Pref. (case 10) and Naka, Ibaraki Pref. (case 11) by Typhoon Hagibis in October 2019 [36]; flooding in Chiba Pref. (case 12) by an extratropical cyclone in October 2019 [37]. Figure 1 shows these locations of the flood events.

Table 1. The Advanced Land Observing Satellite-2 (ALOS-2) test data used in this study.

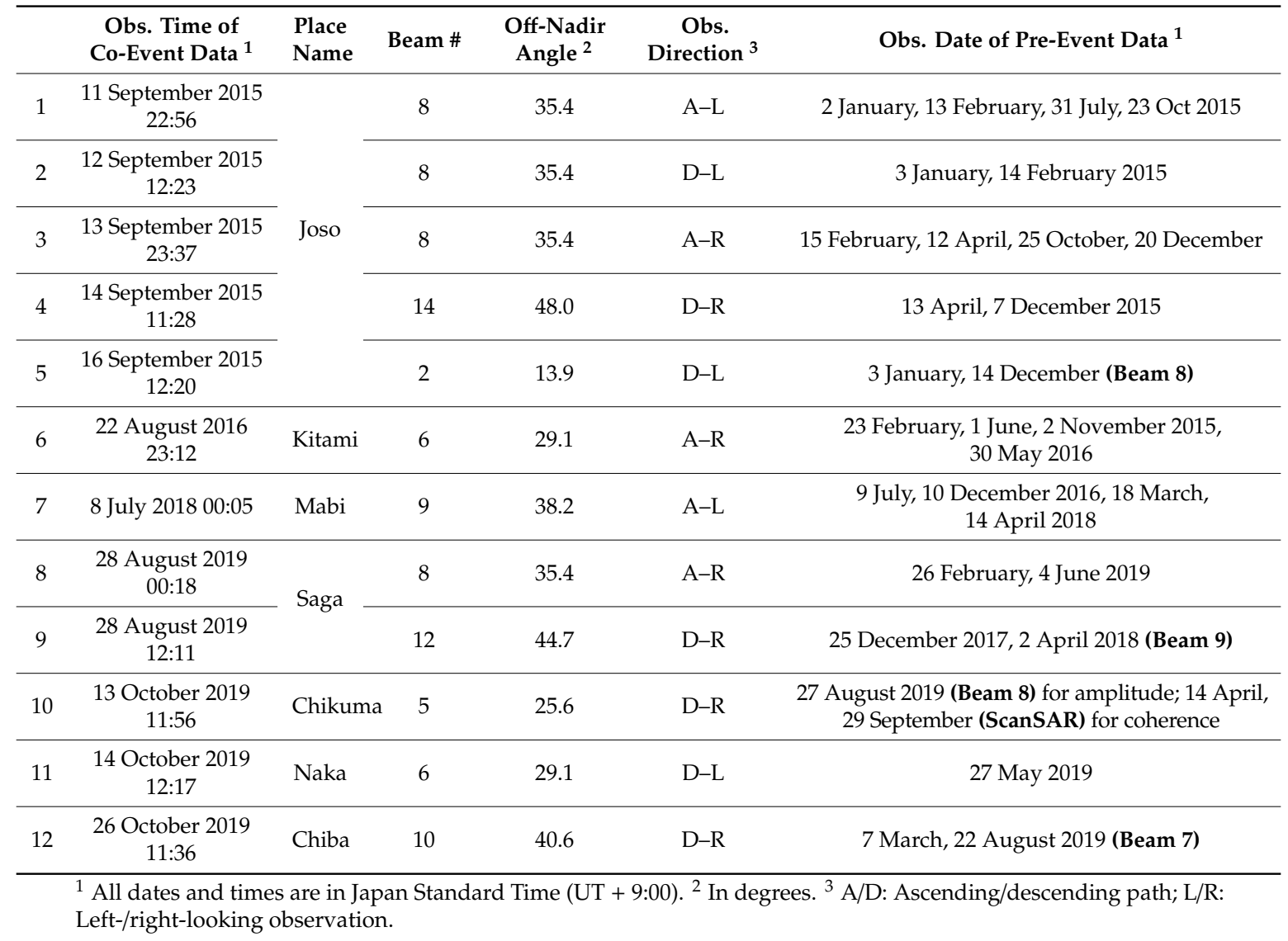



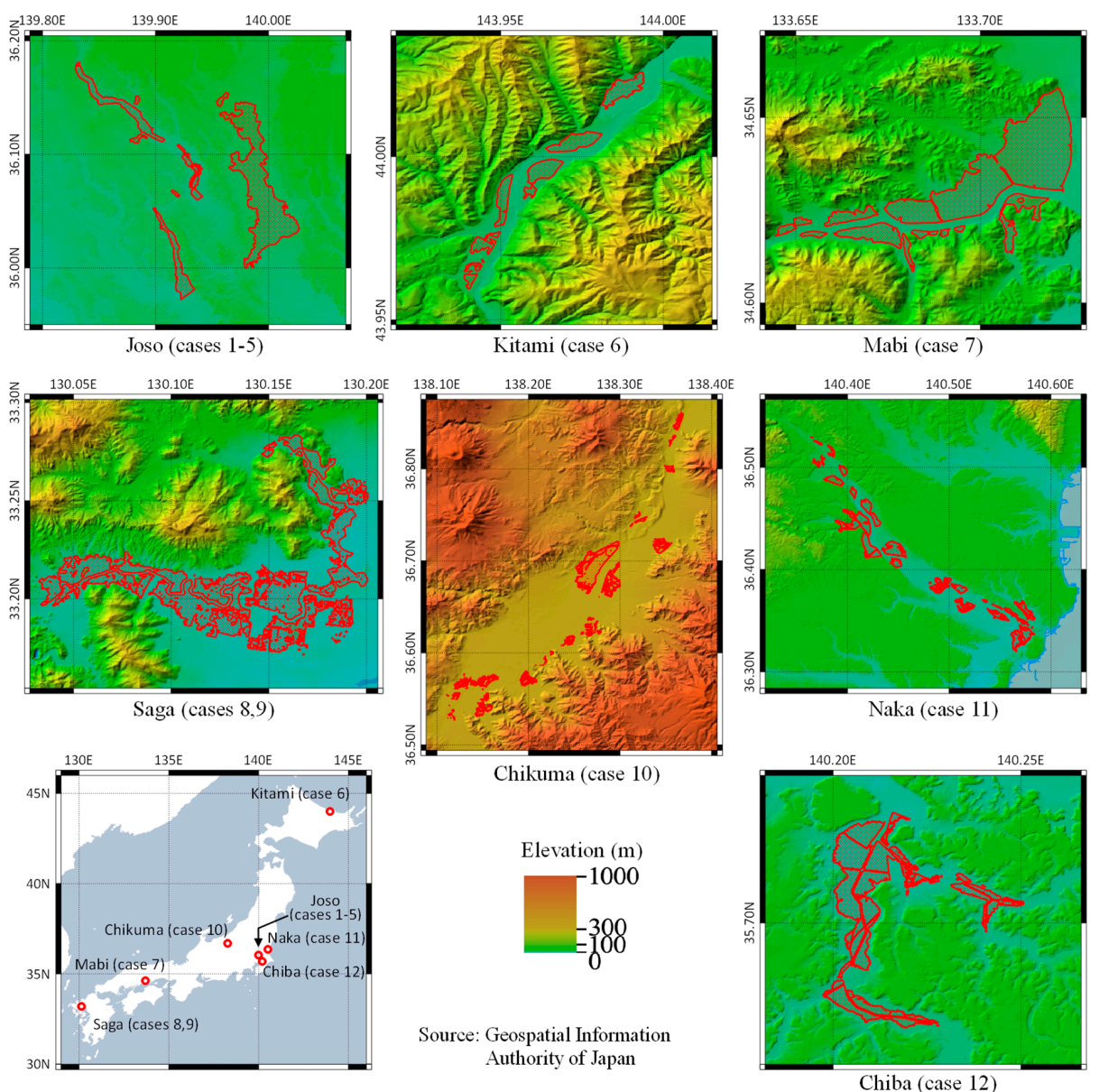

Figure 1. The seven flood-event locations examined in this study. Red polygons show the reference flood maps available from GSI, while the base map shows the elevation (m).

All of the co-event ALOS-2 data used in this study were acquired using 3-m resolution Stripmap mode with HH-polarization due to data availability. Pre-event archived data with the same beam (the same off-nadir angle) as co-event data were required for InSAR, which is effective for flood detection in built-up areas. However, in cases 5, 9, 10, 11, and 12, pre-event data with different beams were used because of a lack of data. In case 10, 50-m resolution ScanSAR data were used for InSAR. In summary, data of cases 5, 9, 11, and 12 cannot detect built-up area flooding accurately, but this was not a significant problem because there were only a few buildings at these sites.

We applied data using beam 14 or lower $\left(<48^{\circ}\right.$ off-nadir angles) because observations with excessively large off-nadir angles result in poor accuracy for flood detection [10]. The use of lower off-nadir angles also avoided radar shadows in mountainous areas.

The original ALOS-2 data used in our processing were the Standard Product Level 1.1, which is single-look complex (SLC) data processed and distributed by the Japan Aerospace Exploration Agency (JAXA).

\subsection{Flood Simulation Data by TE}

We used quasi-real-time flood simulation data processed and provided by a Japanese regional version of TE, TE-Japan [27], developed jointly by the University of Tokyo and JAXA. TE-Japan has been providing various physical quantities hourly with a $1 / 60^{\circ}$-grid (corresponding to $1.5-\mathrm{km}$ resolution) in Japan [29].

TE-Japan integrates surface meteorological data from the Meso-Scale Model by Japan Meteorological Agency (JMA-MSM), the hydrologic land surface model (Minimal Advanced Treatments of Surface 
Integration and RunOff, MATSIRO) [38,39], and the hydrodynamic river model (Catchment-based Macro-scale Floodplain model, CaMa-Flood) [40,41]. By giving surface meteorological data from the JMA-MSM, MATSIRO solves the water and energy interactions between land and atmosphere. MATSIRO is a grid-based one-dimensional vertical simulation model and does not consider water and heat transfer to or from neighboring grids. To calculate horizontal water movement on the land surface, CaMa-Flood calculates the local inertial equation [42] as follows:

$$
\frac{\partial Q}{\partial t}+g A \frac{\partial h}{\partial t}+g A \frac{\partial z}{\partial t}+\frac{g n^{2}|Q| Q}{R^{4 / 3} A}=0
$$

where $Q$ is the river discharge, $A$ is the flow cross-section area, $h$ is the flow depth, $z$ is the bed elevation, $R$ is the hydraulic radius, $g$ is the gravitational acceleration, and $n$ is the Manning's friction coefficient ( $n=0.03$ in this model). This equation is based on the Saint-Venant equation, and the first, second, third, and fourth terms represent local acceleration, water pressure, terrain gradient, and friction slope, respectively. The variables $x$ and $t$ are the flow distance and time. CaMa-Flood assumes a simple cross-section for river channels (rectangular) and flood plains (trapezoidal), and the flood area is indirectly obtained using the cross-sectional shape and depth of the water.

This study used flooded area fraction (FLDFRC) obtained from TE. FLDFRC is the fraction of the grid cell that is flooded. Since CaMa-Flood is a model with a relatively lower spatial resolution (1.5 km in TE-Japan) than SAR measurements and assumes a simple cross-sectional shape for a water body, FLDFRC serves as a proxy for a large-scale phenomenon rather than a deterministic indicator of local-scale floods. Figure 2 shows examples of FLDFRC on 11 September 2015 (during the Joso flooding) and 8 July 2018 (Mabi flooding).

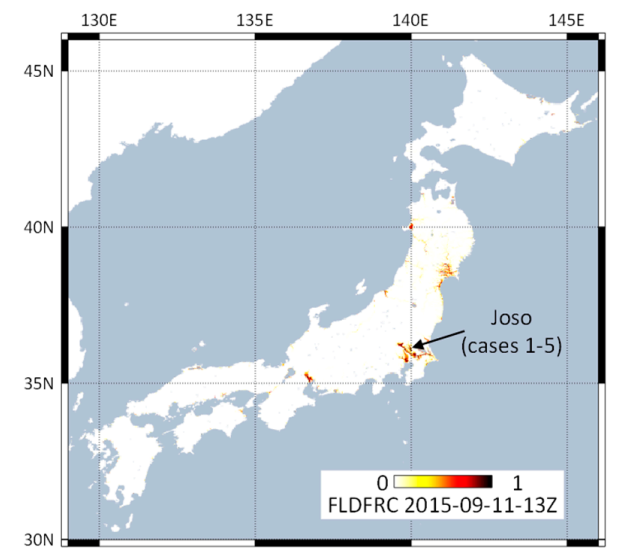

(a)

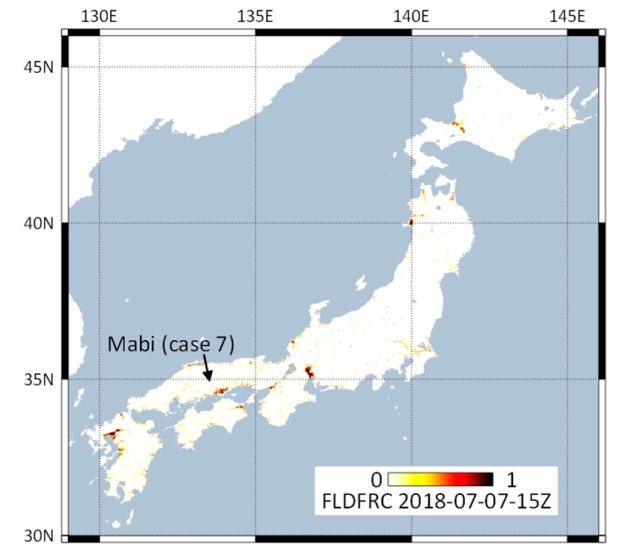

(b)

Figure 2. Flood fraction data provided by the Today's Earth (TE) on (a) 11 September 2015 (Joso flood) and (b) 8 July 2018 (Mabi flood).

\subsection{Other Ancillary Data}

A land-cover/land-use map was used for correcting misclassifications that occurred in specific land use. This study used the High-Resolution Land-Use and Land-Cover map (HRLULC), a 10-m resolution 10-category land-use/land-cover product processed and provided by JAXA.

Terrain data (digital elevation model, DEM) were used in the orthorectification of SAR data. This study used the DEM from the Fundamental Geospatial Data provided by the Geospatial Information Authority of Japan (GSI), with 10-m resolution and approximately 5-m elevation accuracy.

For evaluating our method, we compared our flood detection results with the reference flood extent data available from GSI [32-37] (shown in Figure 1 and listed in Table 2). The disaster survey experts in GSI produced these maps by manually interpreting high-resolution (20 $\mathrm{cm}$ or worse) aerial photographs. 
Table 2. Reference data provided by the Geospatial Information Authority of Japan (GSI) for validation.

\begin{tabular}{|c|c|c|c|}
\hline Case No. of Table 1 & Place Name & Time Stamp ${ }^{1}$ & Reference \\
\hline 1 & \multirow{5}{*}{ Joso } & 11 September 2015 13:00 & \multirow{5}{*}{ [32] } \\
\hline 2 & & 12 September 2015 15:30 & \\
\hline 3 & & 13 September 2015 10:40 & \\
\hline 4 & & 14 September 2015 09:30 & \\
\hline 5 & & 16 September 2015 10:20 & \\
\hline 6 & Kitami & 23 August 2016 15:00 & [33] \\
\hline 7 & Mabi & 8 July 2018 14:00 & [34] \\
\hline 8,9 & Saga & 28 August 2019 15:00 & [35] \\
\hline 10 & Chikuma & 13 October 2019 13:00 & \multirow{2}{*}[36]{} \\
\hline 11 & Naka & 14 October 2019 01:00 & \\
\hline 12 & Chiba & 26 October 2019 08:30 & [37] \\
\hline
\end{tabular}

\section{Methods}

\subsection{Pre-Processing}

Figure 3 details the pre-processing for preparing SAR amplitude, coherence, FLDFRC, and HRLULC images, which were used in the main processing (Section 3.2).

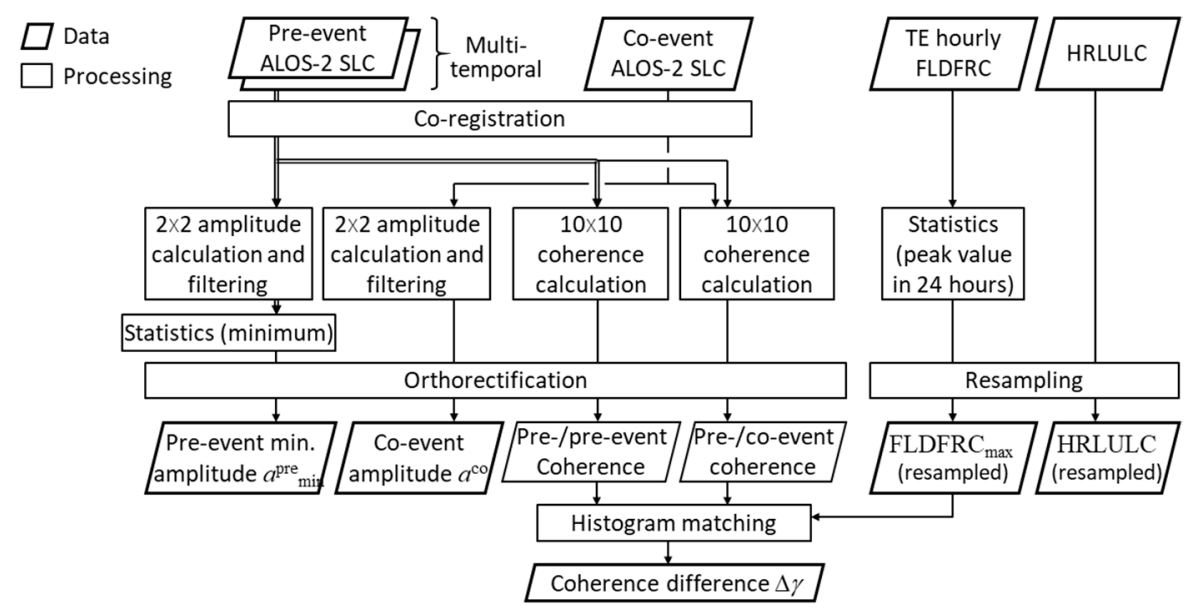

Figure 3. Flowchart showing the pre-processing of this study.

The co-event SAR data were co-registered with the latest pre-event SAR data. Since rapid products of co-event data may have a larger geometric error in actual disaster response, pre-event data are more reliable in geometry and should be used as the basis for co-registration.

Then, multi-looked $(2 \times 2$ pixels) amplitude images were made from co-registered SAR data and speckle-filtered by a Frost filter [43] with a $3 \times 3$-pixel sliding window. Frost filter is computationally efficient for preserving point targets and thus effective for flood detection [44]. A larger filter window (e.g., $5 \times 5$ pixels) reduces the more minute misclassifications; however, in this study, it was not effective because the final polygonization process significantly reduced the noise of classification results. If multiple pre-event amplitude images $a^{\mathrm{pre}_{i}}$ were available, their minimum value $a^{\mathrm{pre}}{ }_{\text {min }}$ was computed for each pixel and used with the co-event amplitude image $a^{\mathrm{co}}$. Other statistics such as the maximum value, average, and temporal variance may be useful but were not used in this study for reasons of simplicity and computational efficiency. The minimum value is the most important in detecting peak seasonal inundation (typically in rice paddies) and to prevent these areas from being falsely detected as flooded. 
Interferometric coherences were calculated in a $10 \times 10$-pixel window, i.e., a $5 \times 5$-pixel sliding window, following $2 \times 2$ pixel multi-looking for the pair of co-event and latest pre-event images $\left(\gamma_{\text {pre-co }}\right)$, and the pair of latest two pre-event images ( $\left.\gamma_{\text {pre-pre }}\right)$. Many other combinations of coherence pairs can be considered but were not used to avoid complexity. The coherence can be decreased not only by flooding but also by factors such as spatial and temporal decorrelation, and thermal noise [45]. In the case of ALOS-2, temporal decorrelation may be significantly large because of the long temporal distance of observations. To compensate for decorrelations that were not related to flooding, we applied histogram matching to the two coherence images and then calculated the difference, i.e., $\Delta \gamma=\gamma_{\text {pre-co }}-\gamma_{\text {pre-pre. }}$ As it turned out that normal histogram matching overcorrects the decorrelation, we proposed a masked histogram matching (detailed in Appendix A).

Hourly FLDFRC data around the time of SAR observation can be used as prior information on flood risk. However, because of the nature of the model-based simulation, the simulated flood has a temporal error. For this reason, the temporal peak value of FLDFRC over $24 \mathrm{~h}, \mathrm{FLDFRC}_{\max }$, was used to account for the peak of flood probability.

Finally, all SAR images, $a^{\mathrm{co}}, a^{\mathrm{pre}}{ }_{\mathrm{min}}$, and $\Delta \gamma$ were orthorectified and geocoded from the radar coordinate to the Universal Transverse Mercator (UTM) projection with 5-m spatial resolution. The FLDFRC max $_{\text {and }}$ aRLULC images, which were originally provided in equatorial latitude/longitude projection, were also re-sampled to the same projection and resolution as the SAR data.

\subsection{Main Processing-Flood Detection}

Our method employed two types of complementary data, i.e., low-resolution simulation data (FLDFRC) and high-resolution SAR data. The pre-processed SAR data (co-event amplitude, pre-event minimum amplitude, and the difference in coherence) were unified into a random vector $x=\left(a^{\mathrm{co}}, a^{\mathrm{pre}}{ }_{\min }, \Delta \gamma\right)^{\mathrm{T}}$ and used for pixel-based classification; $\mathrm{FLDFRC}_{\max }$ was used as a prior probability of floods in Bayesian inference.

To reduce the computation time, pixels with significantly low flood probability ( LLDFRC $_{\max }<0.05$ ) were masked and excluded from processing.

Since flooded areas can have different characteristics in SAR images depending on the land-cover type, a four-category classification was initially performed: $F_{1}$ : permanent no water; $F_{2}$ : permanent water (non-flooded); $\mathrm{F}_{3}$ : open-water flooding; $\mathrm{F}_{4}$ : flooded built-up area. Figure 4 depicts a schematic illustration of the four categories. Similar to Giustarini et al. [31], the conditional probability $P\left(\mathrm{~F}_{i} \mid x\right)$ was computed from Bayesian inference as follows:

$$
P\left(\mathrm{~F}_{i} \mid \boldsymbol{x}\right)=\frac{P\left(\mathrm{~F}_{i}\right) P\left(\boldsymbol{x} \mid \mathrm{F}_{i}\right)}{\sum_{j=1}^{4} P\left(\mathrm{~F}_{j}\right) P\left(\boldsymbol{x} \mid \mathrm{F}_{j}\right)},
$$

where $P\left(\mathrm{~F}_{i}\right)$ is the prior probability computed from FLDFRC max $\ln \left(x \mid \mathrm{F}_{i}\right)$ is the probability density function and is described in Equation (4). The denominator of Equation (2) is the total probability density function of $x$. Since FLDFRC max $_{\text {ax }}$ represents the peak value of flood risk over $24 \mathrm{~h}$, it inevitably tends to overestimate the extent of flooding. Thus, similar to D'Addabbo et al. [30], we used a logistic function to convert FLDFRC $_{\max }$ to the prior probability as follows:

$$
\begin{gathered}
P\left(\mathrm{~F}_{1}\right)=P\left(\mathrm{~F}_{2}\right)=(1-f) / 2, \\
P\left(\mathrm{~F}_{3}\right)=P\left(\mathrm{~F}_{4}\right)=f / 2, \\
f=\frac{A}{1+B \exp \left(\text { FLDFRC }_{\max }-C\right)},
\end{gathered}
$$

where $A, B$, and $C$ are parameters of the logistic function; we set $A=0.5,1 / B=0.05, C=0.2$ (detailed in Appendix B). The probability density function $P\left(x \mid \mathrm{F}_{i}\right)$ in Equation (2) is a Gaussian distribution:

$$
P\left(x \mid \mathrm{F}_{i}\right)=\mathrm{N}\left(\boldsymbol{\mu}_{i}, \boldsymbol{\sigma}\right),
$$

where $\mathrm{N}$ represents Gaussian distribution and $\mu_{i}$ and $\sigma$ are its parameters, empirically defined as shown in Table 3. For instance, $F_{3}$ (open-water flooding) was modeled as smaller co-event amplitude 
$\left(a^{\mathrm{CO}}=t_{a}-\varepsilon_{a}\right)$, larger pre-event amplitude $\left(a_{\min }^{\mathrm{pre}}=t_{a}+\varepsilon_{a}\right)$, and small change in the coherence $(\Delta \gamma \sim 0)$. $t_{a}$ (threshold of amplitude for distinguishing water and no water) was set based on a previous study, in the case of beam 8 , for instance, $-14 \mathrm{~dB}$ [10]. The previous study intensively investigated the threshold dependency of flood detection accuracy and proved that small variations in a threshold of $\sim 1 \mathrm{~dB}$ did not significantly affect accuracy; this enabled us to use coarse thresholds with $1 \mathrm{~dB}$ steps. The smaller the incidence angle, the larger the threshold required because of the large backscattering at steep angles. The slightly high thresholds at large incidence angles (beam 12 and later) stem from the high noise level at shallow angles and long distances. $\varepsilon_{a}$ is the deviation of the probability density function, and the larger the $\varepsilon_{a}$, the fuzzier the flood indication in SAR data. At large incidence angles, the backscatter from rough soil is small and easily confused with water [46]; hence, we set a larger $\varepsilon_{a}$, so that the prior probability contributed more to flood detection. $\mathrm{F}_{4}$ (flooded built-up area) was modeled as a large decrease in coherence due to decorrelation $(\Delta \gamma<-0.3)$ caused by changes in the propagation path of microwaves.

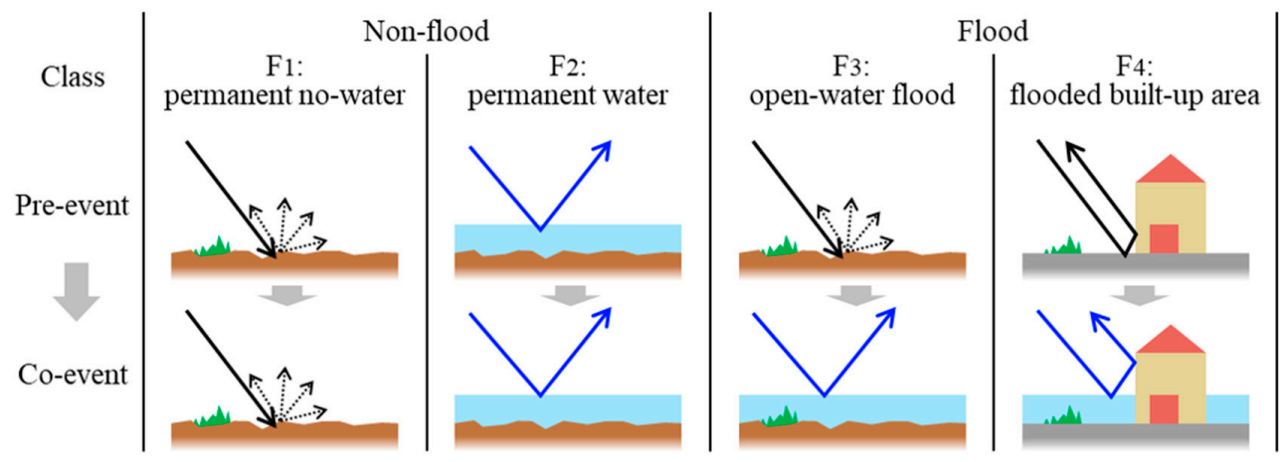

Figure 4. Schematic illustration of the four categories of flood/non-flood states adopted in this study.

Table 3. (a) Parameters of the probability density function; (b) values of the parameters for each beam of the ALOS-2 3-m mode data.

(a)

\begin{tabular}{|c|c|c|c|c|c|c|}
\hline$\mu_{1}$ & $\mu_{2}$ & $\mu_{3}$ & $\mu_{4}$ & & $\sigma$ & \\
\hline$t_{a}+\varepsilon_{a}$ & $t_{a}-\varepsilon_{a}$ & $t_{a}-\varepsilon_{a}$ & $t_{a}+\varepsilon_{a}$ & $\varepsilon_{a}$ & 0 & 0 \\
\hline$t_{a}+\varepsilon_{a}$ & $t_{a}-\varepsilon_{a}$ & $t_{a}+\varepsilon_{a}$ & $t_{a}+\varepsilon_{a}$ & 0 & $\varepsilon_{a}$ & 0 \\
\hline$t_{\Delta \gamma}+\varepsilon_{\Delta \gamma}$ & $t_{\Delta \gamma}+\varepsilon_{\Delta \gamma}$ & $t_{\Delta \gamma}+\varepsilon_{\Delta \gamma}$ & $t_{\Delta \gamma}-\varepsilon_{\Delta \gamma}$ & 0 & 0 & $\varepsilon_{\Delta \gamma}$ \\
\hline
\end{tabular}

(b)

\begin{tabular}{|c|c|c|c|c|c|}
\hline Beam No. & Off-Nadir (deg) & $t_{a}(\mathrm{~dB})$ & $\varepsilon_{a}(\mathrm{~dB})$ & $t_{\Delta \gamma}$ & $\varepsilon_{\Delta \gamma}$ \\
\hline 1 & 9.6 & -10 & 1 & \multirow{14}{*}{-0.3} & \multirow{14}{*}{0.1} \\
\hline 2 & 13.9 & -11 & 1 & & \\
\hline 3 & 18.0 & -11 & 1 & & \\
\hline 4 & 21.9 & -11 & 1 & & \\
\hline 5 & 25.6 & -11 & 1 & & \\
\hline 6 & 29.1 & -12 & 1 & & \\
\hline 7 & 32.7 & -13 & 1 & & \\
\hline 8 & 35.4 & -14 & 1 & & \\
\hline 9 & 38.2 & -14 & 1 & & \\
\hline 10 & 40.6 & -15 & 2 & & \\
\hline 11 & 42.7 & -15 & 2 & & \\
\hline 12 & 44.7 & -14 & 2 & & \\
\hline 13 & 46.4 & -14 & 2 & & \\
\hline 14 & 48.0 & -14 & 3 & & \\
\hline
\end{tabular}


Our method still works even if some data are not available. If SAR coherence information is not available, the number of classification categories will be reduced (only $F_{1}$ to $F_{3}$ ), and the dimension of the random vector will also be reduced, i.e., $x=\left(a^{\mathrm{co}}, a^{\mathrm{pre}}{ }_{\min }\right)^{\mathrm{T}}$. In this case, built-up area floods cannot be detected well because of the lack of coherence information. If there is no FLDFRC or similar prior information of the flood, equal prior probability $(f=0.5)$ can be given so that our method still works. On the contrary, it is also possible to expand the numbers of the classification categories and random variables. For instance, flooded vegetation, which can be detected by an increase in double-bounce (but was ignored in the present study) can be included by adding a new category $\mathrm{F}_{5}$ (flooded vegetation) and expanding the random vector as $\left(a^{\mathrm{co}}, a^{\mathrm{pre}}{ }_{\min }, \Delta \gamma, \Delta a\right)^{\mathrm{T}}$, where $\Delta a$ is the increase in amplitude (co-event - pre-event).

The initial four-category classification map was obtained by selecting the category that has the largest posterior probability given by Equation (2). However, floods in rice paddies, which should be classified as $\mathrm{F}_{3}$ (open-water flooding), tend to be classified as $\mathrm{F}_{2}$ (permanent water) because of irrigation. To correct this misclassification, the following correction was applied to the pixels in rice paddies: pixels classified as $F_{2}$ were reclassified as $F_{3}$ if $5 \%$ of the pixels in a $21 \times 21$ window were $F_{3}$. This correction is based on the fact that, if paddy levees and roads around paddy fields are submerged, the inner paddy fields could also be regarded as floods. The window size used in this correction is based on the typical size of paddy fields in Japan (100 m 20 pixels).

Then, a binary (flood and non-flood) map was obtained by unifying $F_{1}$ and $F_{2}$ to non-flooded, and $\mathrm{F}_{3}$ and $\mathrm{F}_{4}$ to flooded. Then, we polygonised the binary map and eliminated minute polygons smaller than 400 square meters, equivalent to a minimum mapping unit (MMU) of 44 pixels. Similar MMU values were used in other studies, e.g., 30 pixels [25]. To prevent a possible increase in data size due to unexpected errors, we also introduced a failsafe to remove polygons out of the top 200 largest polygons in the image. The data size of the initial polygon data was redundantly large because all pixels on the boundaries of the flood areas were converted into vertices of the polygon. The shape of the polygon was simplified by the Ramer-Douglas-Peucker algorithm (tolerance factor $\varepsilon=20 \mathrm{~m}$ in this study) [47].

\subsection{Accuracy Evaluation}

We compared the obtained flood maps with the reference data from GSI and calculated four accuracy indicators: Kappa coefficient $\kappa$, a robust accuracy index particularly in an unbalanced dataset (flood and non-flood samples are not in equal numbers) [48]; Recall, i.e., the fraction of actual floods that are correctly detected (also known as a true positive rate); Precision, i.e., the fraction of detected flood areas that actually flood; F-measure $F$, a harmonic mean of Recall and Precision. Overall accuracy (the fraction of all pixels classified correctly) was not used in this study because it overestimates the accuracy in unbalanced datasets [10].

\section{Results}

\subsection{Overview of the Results}

Figure 5 shows the step-by-step outputs of our method for case 7, for instance: initial classification maps before (a) and after (b) the rice-paddy correction, and polygons of flood areas before (c) and after (d) simplification; (a)-(d) are results obtained using FLDFRC. Figure 5e shows the simplified polygon without using FLDFRC, for comparison. The result obtained using FLDFRC (d) is more similar to the reference data (f), while the result without FLDFRC (e) contains several over-detections around the actual flood areas. Rice-paddy correction (from (a) to (b)) using HRLULC effectively improved the under-detection of the flood area. 


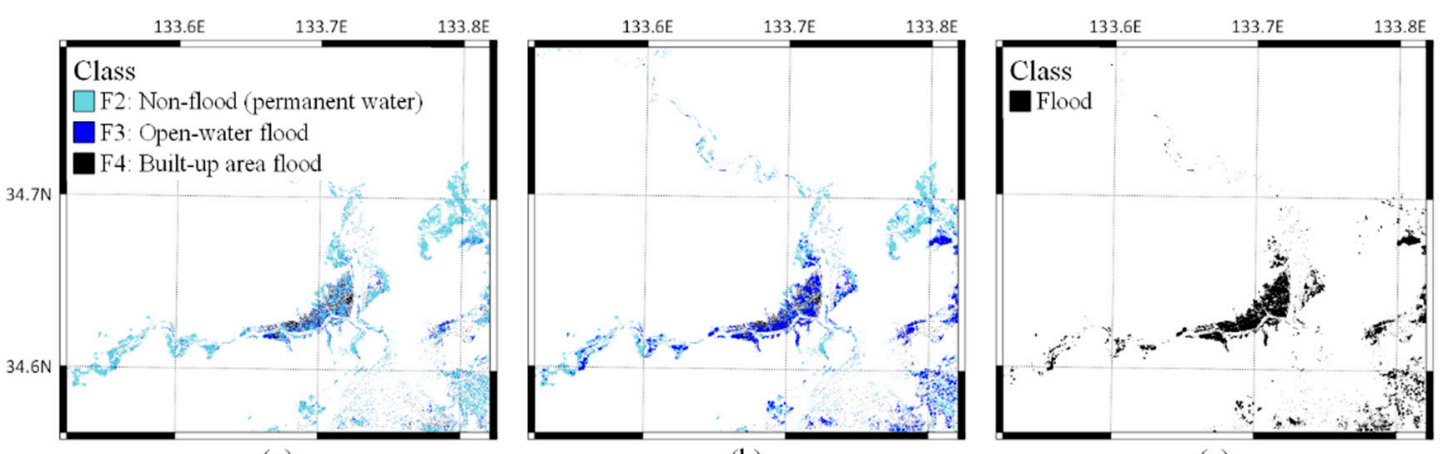

(a)

(b)

(c)

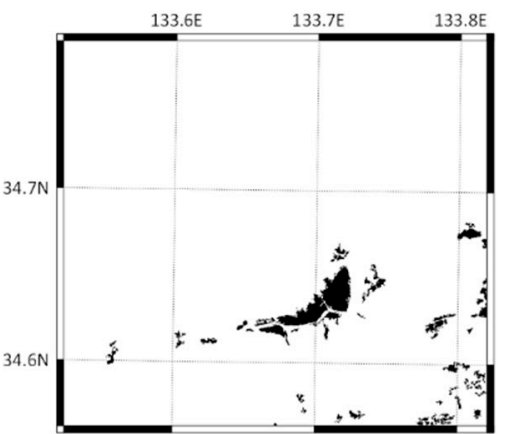

(d)

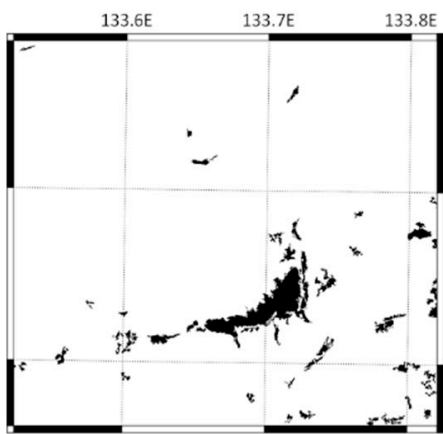

(e)

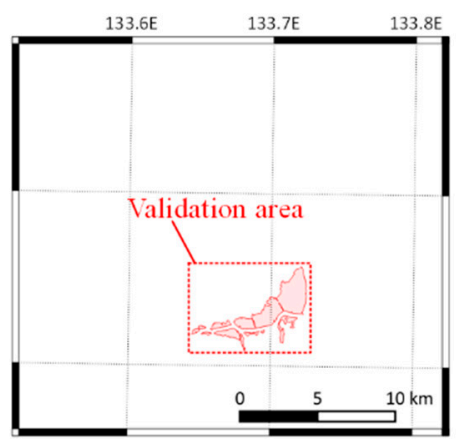

(f)

Figure 5. Step-by-step outputs of our method. (a) Initial classification map before the rice-paddy correction; (b) classification map after the rice-paddy correction; (c) polygonised flood area before simplification; (d) simplified flood-area polygon; (a-d) are results obtained using flood fraction (FLDFRC);

(e) the result of the simplified polygon obtained without using FLDFRC; (f) reference data by GSI.

Table 4 and Figure 6 summarize the flood detection accuracy and computation time for each case. They compare the results with and without using FLDFRC to show its effectiveness. For most of the cases, the use of FLDFRC improved accuracy and reduced computation time. Case 7 had the highest accuracy $(\kappa \sim 0.9)$, cases 4,5 , and 9 had low accuracy $(\kappa \sim 0.5)$, and the averaged accuracy was about $\kappa \sim 0.7$. Precision tended to be higher than Recall.

Table 4. The accuracies of floods detected by ALOS-2 data, with and without flood simulation.

\begin{tabular}{|c|c|c|c|c|c|c|c|c|c|c|c|}
\hline \multirow{2}{*}{$\begin{array}{c}\text { Case } \\
\text { No. }\end{array}$} & \multirow{2}{*}{$\begin{array}{l}\text { Obs. Date Of } \\
\text { Co-Event Data }\end{array}$} & \multirow{2}{*}{ Beamno. } & \multirow{2}{*}{$\begin{array}{l}\text { Off-Nadir } \\
\text { Angle }\end{array}$} & \multicolumn{4}{|c|}{ Accuracy (Using Simulation) } & \multicolumn{4}{|c|}{ Accuracy (Without Simulation) } \\
\hline & & & & $\kappa$ & $F$ & Prec. & Recall & $\kappa$ & $F$ & Prec. & Recall \\
\hline 1 & 11 September 2015 & 8 & 35.4 & 0.673 & 0.706 & 0.727 & 0.685 & 0.691 & 0.723 & 0.718 & 0.727 \\
\hline 2 & 12 September 2015 & 8 & 35.4 & 0.655 & 0.735 & 0.617 & 0.910 & 0.591 & 0.691 & 0.555 & 0.916 \\
\hline 3 & 13 September 2015 & 8 & 35.4 & 0.769 & 0.793 & 0.904 & 0.707 & 0.769 & 0.793 & 0.931 & 0.691 \\
\hline 4 & 14 September 2015 & 14 & 48.0 & 0.477 & 0.509 & 0.652 & 0.418 & 0.315 & 0.372 & 0.358 & 0.388 \\
\hline 5 & 16 September 2015 & 2 & 13.9 & 0.501 & 0.508 & 0.674 & 0.408 & 0.481 & 0.488 & 0.672 & 0.383 \\
\hline 6 & 22 August 2016 & 6 & 29.1 & 0.658 & 0.666 & 0.882 & 0.535 & 0.541 & 0.555 & 0.573 & 0.539 \\
\hline 7 & 8 July 2018 & 9 & 38.2 & 0.888 & 0.909 & 0.915 & 0.904 & 0.799 & 0.842 & 0.763 & 0.940 \\
\hline 8 & 28 August 2019 & 8 & 35.4 & - & - & 0.667 & - & - & - & 0.568 & - \\
\hline 9 & 28 August 2019 & 12 & 44.7 & 0.477 & 0.550 & 0.657 & 0.473 & 0.455 & 0.544 & 0.554 & 0.535 \\
\hline 10 & 13 October 2019 & 5 & 25.6 & 0.553 & 0.571 & 0.614 & 0.534 & 0.472 & 0.496 & 0.487 & 0.506 \\
\hline 11 & 14 October 2019 & 6 & 29.1 & - & - & 0.705 & - & - & - & 0.381 & - \\
\hline 12 & 26 October 2019 & 10 & 40.6 & 0.789 & 0.819 & 0.870 & 0.773 & 0.739 & 0.783 & 0.692 & 0.902 \\
\hline
\end{tabular}




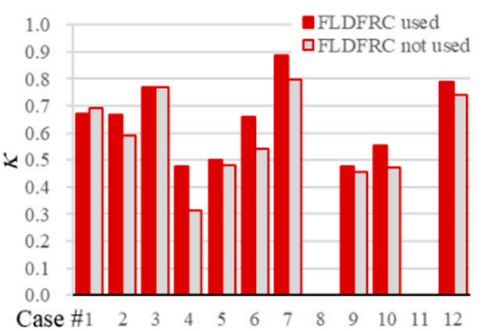

(a)

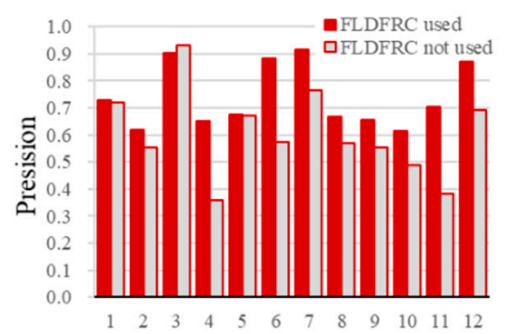

(b)

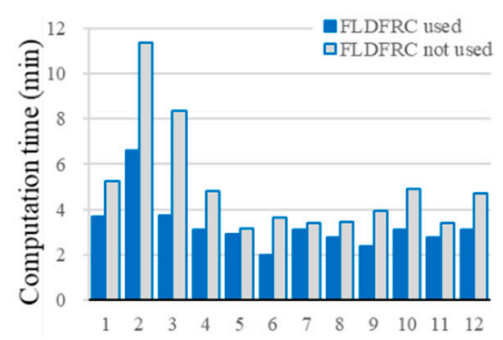

(c)

Figure 6. Comparison of flood detection results with and without FLDFRC (flood simulation): (a) Kappa coefficient $\kappa$; (b) Precision; (c) computation time.

In cases 8 and 11, accuracy validation was difficult because of the large difference in the observation time of the SAR and reference data. We assumed that the reference data capture the peak of the flood area and that the SAR-derived flood area is off-peak and encompassed in the peak flood area. In these cases, only Precision could be computed.

Note that the computation time shown in Figure $6 \mathrm{c}$ is only for main processing (Section 3.2) and does not include the time for pre-processing (3.1) and evaluation (3.3). The process was run on the ALOS Geoscience and Application Processor (AGAP), a subsystem of the ALOS-2 ground system used for processing high-level products) with Intel XEON Gold (2.6 GHz) processors; eight processors are used in parallel.

Figure 7 shows the flood maps obtained using FLDFRC and not using it. As mentioned above, in cases 8 and 11 (not shown in Figure 7), SAR-derived flood maps were small because of observation time differences. For other cases, flood maps similar to the reference data were successfully obtained.

\subsection{Result of Each Flood Event}

From the results of the flood in Joso, the accuracy improvement using FLDFRC was relatively small for the observations at smaller off-nadir angles (cases 1-3 and 5); that is, SAR data could sufficiently detect flood areas without flood simulation in these cases. These results also indicate the expansion of the water area in Watarase Reservoir, the largest flood-control basin in Japan (Figure 7b,d). These are not included in the accuracy verification because there was no reference data outside the verification area. FLDFRC is particularly effective in case 4 , where the off-nadir angle was large. The 24-h maximum value of FLDFRC was based on the time of the first observation (September 11) and used for cases 1 to 5 because FLDFRC was based on a model of the normal shape of rivers and could not simulate prolonged flooding due to levee collapse.

The flood in Kitami (case 6) suffered low coherence in pre-event InSAR data but provided a relatively good result.

The flood in Mabi (case 7) was observed in good conditions; multi-temporal and highly coherent pre-event data were available with the same off-nadir angle. The results agreed well with the reference data; the accuracy was $\kappa=0.8$ without FLDFRC and $\kappa=0.9$ with FLDFRC. The floods detected outside the validation area (blue circles in Figure 7n) were likely the overland floods of rice-paddy fields.

The result for the flood in Saga on 28 August (case 9) was relatively poor because of undetected floods in crop fields (due to the large incidence angle) and built-up areas (due to the lack of coherence information).

The data for the flood in Chikuma (case 10) required extra consideration in the pre-processing. Since there are no interferometric (having the same off-nadir angle) pre-event data by the high-resolution Stripmap mode, pre-event data by the low-resolution ScanSAR mode were used instead. The coherence was calculated with a larger multi-look window, $10 \times 40$ pixels $(2 \times 8$-looks multi-look in range $\times$ azimuth and a $5 \times 5$-pixel sliding window, corresponding to $100-\mathrm{m}$ resolution) to avoid decorrelation due to the different bandwidths and pulse repetition frequencies (PRFs). Although its resolution was 
considerably larger than individual buildings, ScanSAR is still useful for detecting changes in clusters of buildings [49].
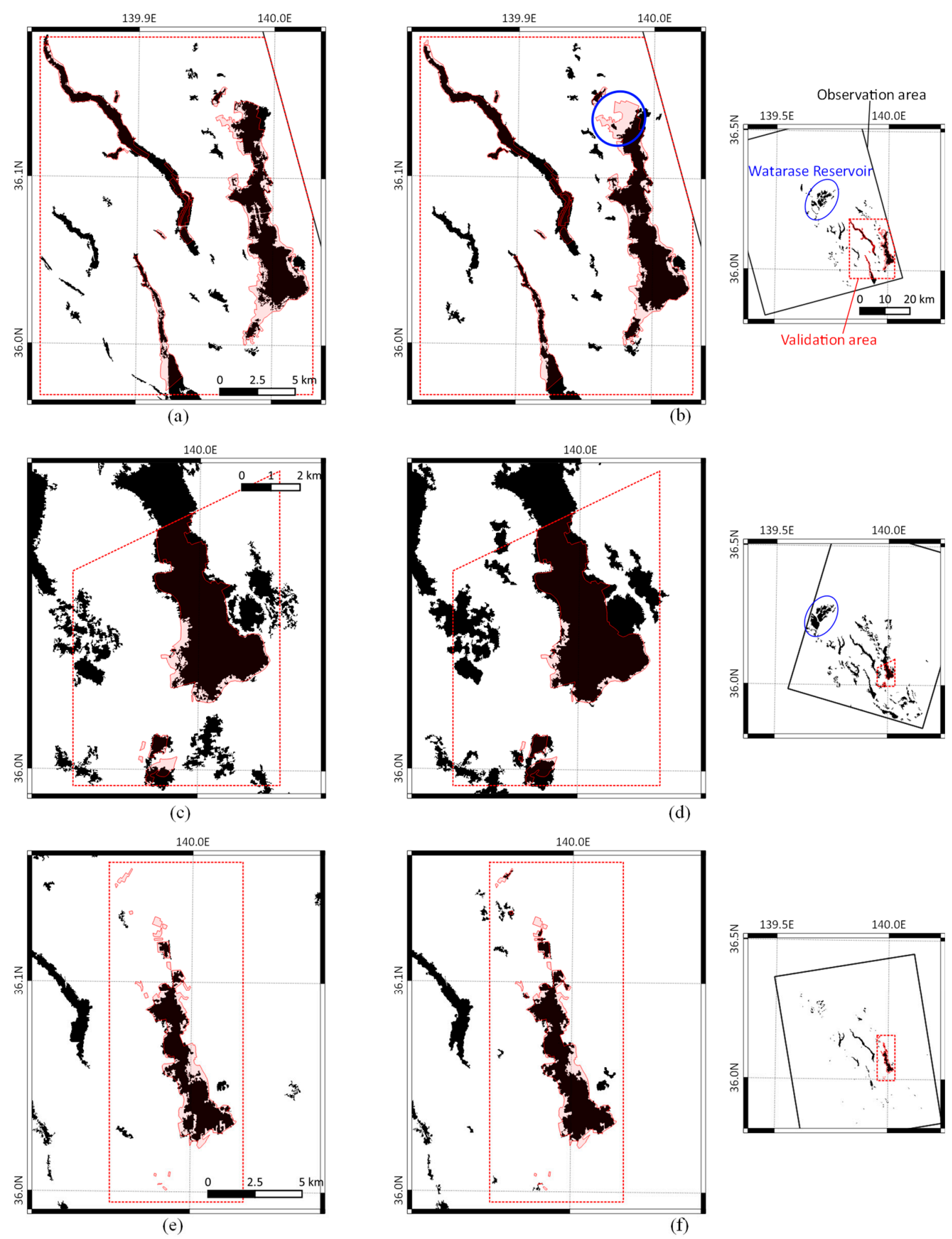

Figure 7. Cont. 

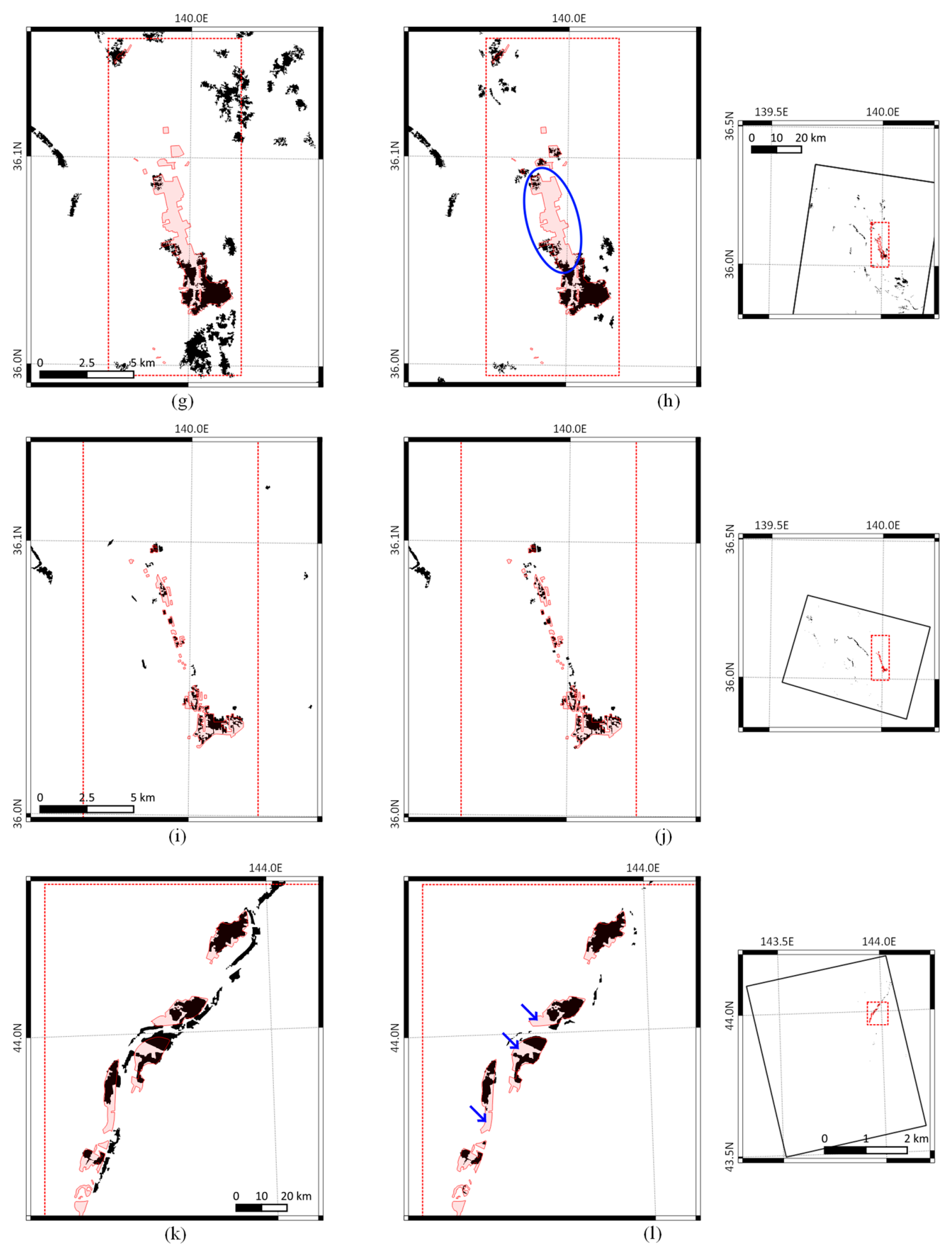

Figure 7. Cont. 


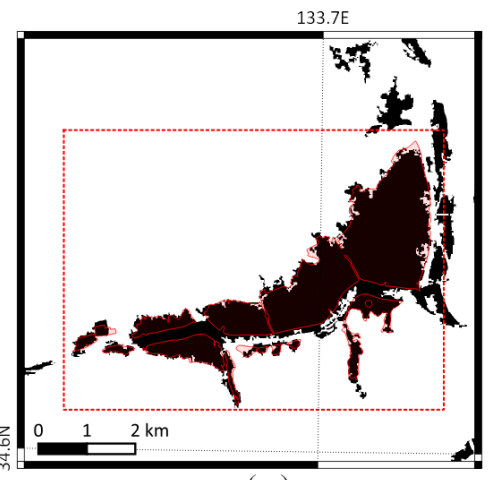

(m)
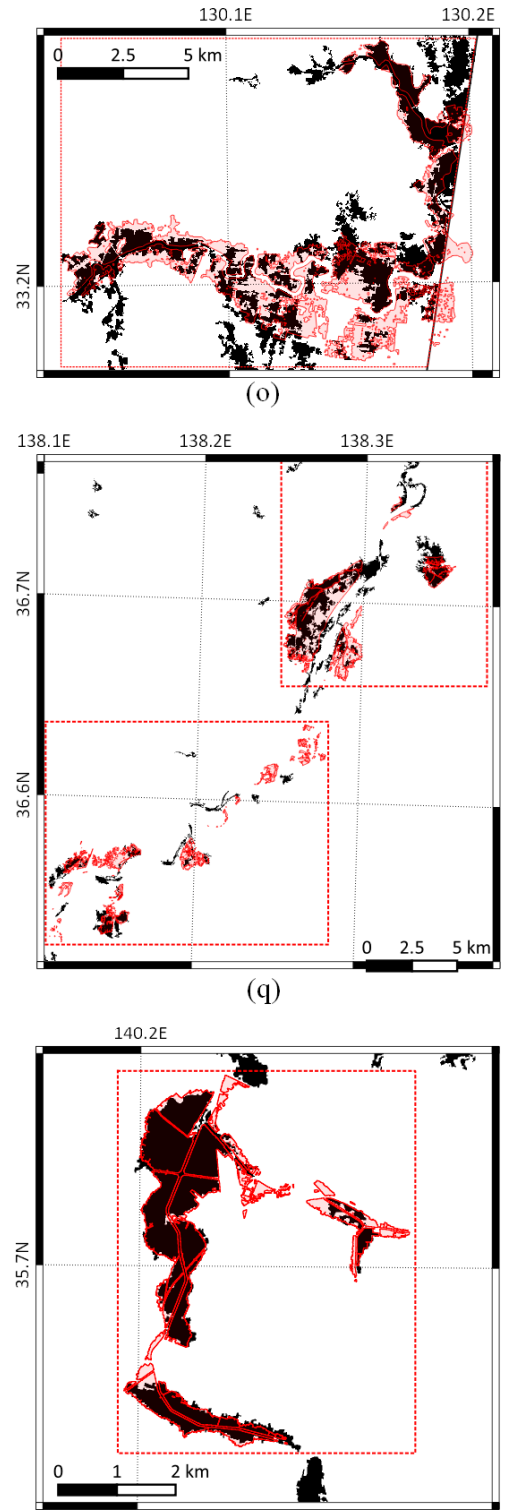

(s)
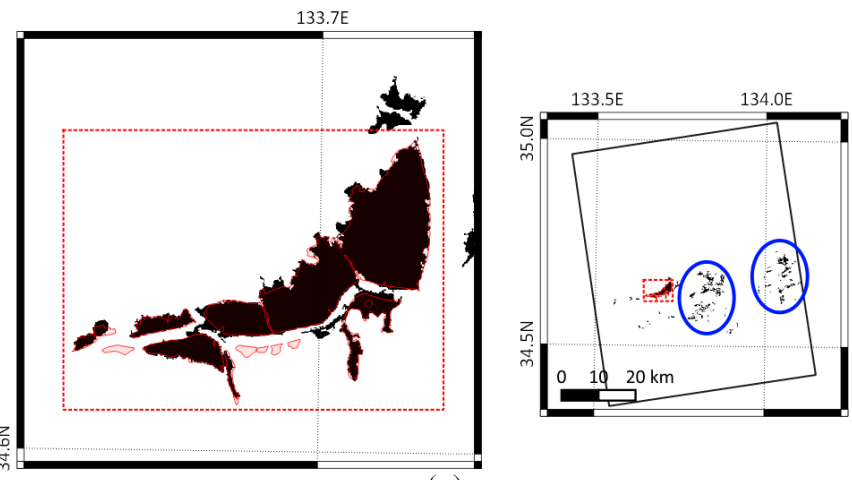

(n)
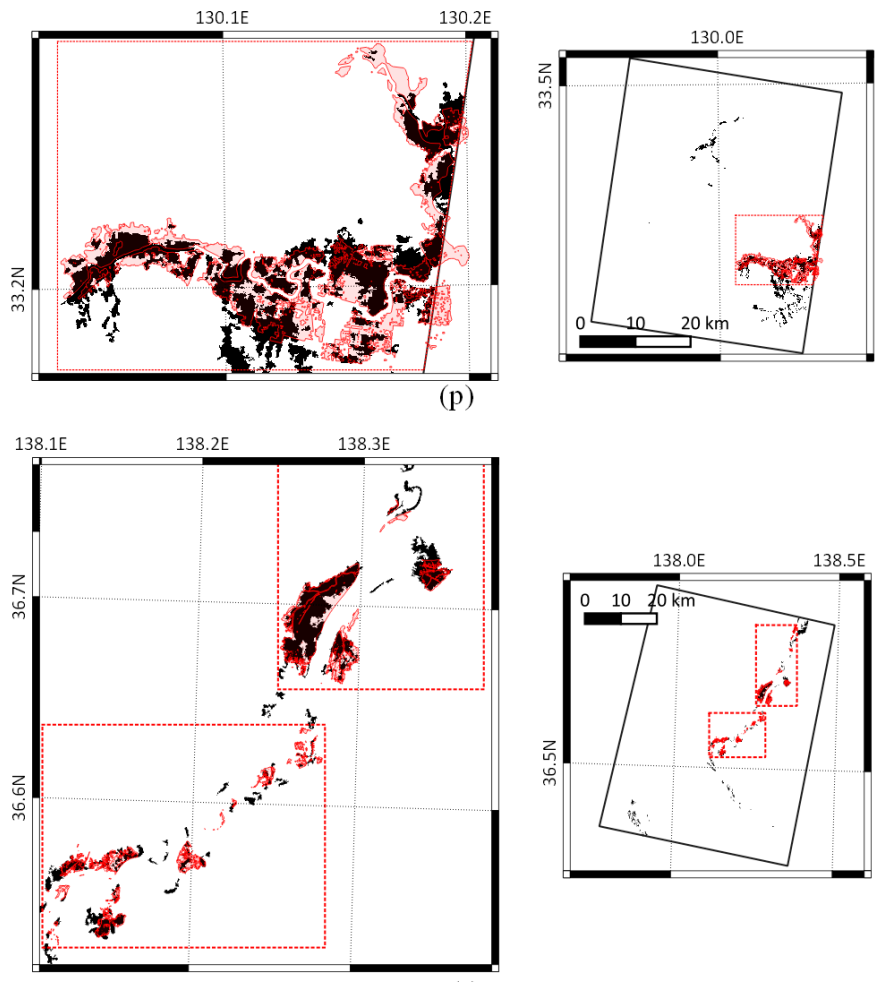

(r)
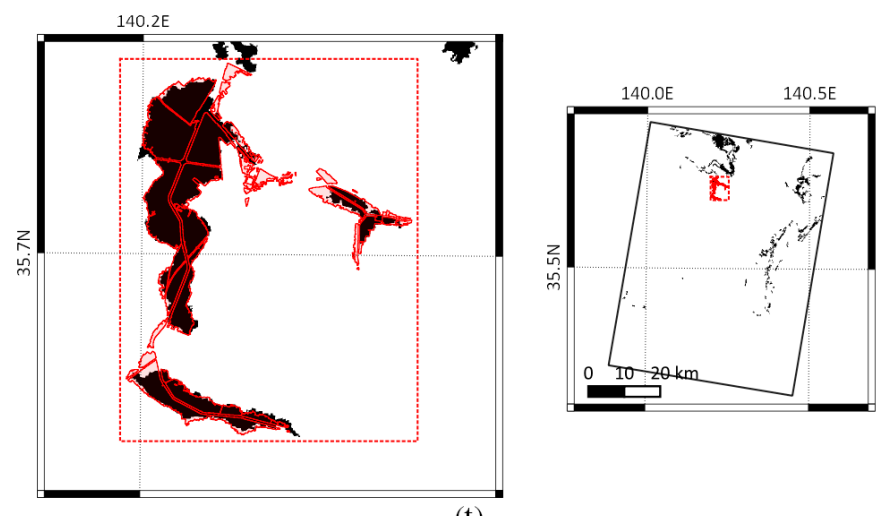

(t)

Figure 7. Flood areas obtained from ALOS-2 data with and without flood simulation (black solid polygon), compared with the reference data (red line polygon); (a,b) show flooding in Joso on 11 September 2015, (case 1), (c,d) on September 12 (case 2), (e,f) on September 13 (case 3), (g,h) on September 14 (case 4), $(\mathbf{i}, \mathbf{j})$ on September 16 (case 5), (k,1) flooding in Kitami on 22 August 2016, (case 6), (m,n) flooding in Mabi on 8 July 2018, (case 7), (o,p) flooding in Saga on 28 August 2019, (case 9), (q,r) flooding in Chikuma on 13 October 2019, (case 10), (s,t) flooding in Chiba on 14 September 2019, (case 12). The left (a,c,e ... ) and right figures $(\mathbf{b}, \mathbf{d}, \mathbf{f} \ldots$... ) represent results using and not using flood simulation, respectively. 


\section{Discussion}

\subsection{The Effect of Using the Flood Simulation}

Using FLDFRC had an impact on the improvement of flood detection accuracy, especially for reducing over-detection. Although the accuracy measures did not appear to have improved significantly in some cases (e.g., case 1 in Table 4), FLDFRC reduced many over-detections outside the validation area (as shown in Figure 3d,e). Improvements outside the validation areas are not reflected in the accuracy measures because of a lack of reference data.

The degree of accuracy improvement depended on the observation conditions of SAR data. The FLDFRC particularly improved results under adverse conditions such as large off-nadir angles. In case 4, which had the largest off-nadir angle in this study, the use of FLDFRC was essential to achieve the minimum requirement of the flood detection accuracy (approximately $60 \%$ for the Japanese disaster community). The effect of FLDFRC for reducing calculation time also depended on the data because, with fewer flood areas simulated, more calculations could be skipped.

As FLDFRC is calculated by assuming a rectangular river channel and a trapezoidal flood plain, without taking into account levee collapse [40], it sometimes underestimates flood probability. In case 1, some floods could be detected without FLDFRC but not when using FLDFRC (indicated by the blue circles in Figure 7b). This error was caused by the very small value of FLDFRC that brought the prior probability to almost zero. The low resolution of FLDFRC (1.5 km in Japan) compared with SAR (5 m in this study) also contributed to these errors. The lower resolution of FLDFRC outside of Japan (25 km) may present a problem when applying our method to a global scale. High-resolution, more accurate flood simulations will be needed for a more accurate estimation of flooding. Although FLDFRC is effective for the coarse estimation of floods, SAR data are still essential for deciding whether flooding has occurred.

\subsection{Accuracy}

The most important factor that influences flood detection accuracy is the off-nadir angle [10]. In this study, the accuracy of cases $4\left(48^{\circ}\right.$ off-nadir angle) and $9\left(45^{\circ}\right)$ was relatively poor. A large, undetected flood in case 4 (blue circle in Figure $7 \mathrm{~g}, \mathrm{~h}$ ) and many discrepancies with the reference data in case 9 (Figure 7p) arose from the misclassification of rice paddies and crop fields. Backscattering from the ground (rough soil or low vegetation) was small at large incidence angles and comparable to that of a water surface [46]. Furthermore, the loss of power due to the long range increased the noise level and made it more difficult to distinguish a water surface.

Even at smaller off-nadir angles, under-detection of floods occurred in the low-backscatter crop fields (e.g., blue arrows in Figure $7 \mathrm{k}, 1$ ). This is a characteristic of the L-band and requires shorter wavelengths (X-and C-bands) for radical improvement.

The quality of archived pre-event data also affected accuracy. Pre-event data that are too old and interferometric pairs that have too large a temporal distance degrade accuracy. As this study performed InSAR processing using temporally distant data, the temporal decorrelation was mistakenly detected as flooding. The long observation interval was due to satellite specification, i.e., ALOS-2 returns to the same path (the same ground track) every 14 days but this does not mean that observations are made every 14 days. As the swath width of the ALOS-2 (3-m resolution Stripmap mode) is approximately $50 \mathrm{~km}$, while the interval of paths is approximately $200 \mathrm{~km}$, it takes 2-3 months to completely cover the land surface. It is expected that this issue will be solved by the follow-on satellite, ALOS-4 [50], which will extend the swath width to $200 \mathrm{~km}$ and enable observations every 14 days. Once the frequency of data availability is increased by ALOS-4, the use of all pre-event data acquired for the preceding year about a disaster will effectively reduce the influences of seasonal changes.

In cases where the off-nadir angle of pre-event data was different from that of co-event data (cases 5, 9, and 12), floods in built-up areas could not be detected because of a lack of coherence information. Case 10 had to use ScanSAR-Strip interferometry, resulting in lower resolution and less 
accuracy due to the different frequency bands and PRFs. Consequently, acceptable accuracy could be obtained from data by beam 14 or less but beams 6 to 9 were preferred because they already had a lot of archived data ready for time-series analysis and interferometric processing.

Many studies have already reported the flood detection accuracy of ALOS-2 using the same reference data as this study, i.e., the Joso (reported accuracies in Kappa or F-measure were 0.6 to 0.7) [10,12,44,51-54], Mabi (reported accuracy 0.8) [54,55], and Chikuma ( 0.5) [49] floods. Compared to these previous studies, our method using FLDFRC naturally obtained higher accuracies because of the contribution of flood simulation. Our results without using FLDFRC tended to be less accurate because some of these past studies used more multi-temporal amplitude/coherence information, which is currently not included in our methods for simplicity. Furthermore, the past studies analyzed a limited number of cases and may be too specific to the test case, resulting in an overestimation of accuracy. Our method was validated with many datasets with a variety of flood events, confirming its robustness and repeatability.

Another major cause of the error was the difference in observation times of the SAR and the reference data. In cases $3,6,7,8$, and 11 , there were SAR/reference time differences of more than $10 \mathrm{~h}$ as shown in Tables 1 and 2. However, case 7 (Mabi) was reservoir-type flooding that did not flow naturally; the large time difference did not significantly affect accuracy.

The present method assumed a simple Bayesian inference and Gaussian distribution that considered only decreases in amplitude and coherence. Thus, other parameters (e.g., amplitude increases caused by the double-bounce effect, more multi-temporal data) and more complex probability distributions should be considered to further improve accuracy.

Table 5 summarizes the characteristics of our methodology in terms of flood detection from ALOS-2 data. Our method is computationally fast and meets user requirements, although its accuracy can be improved. The method requires no parameter adjustments other than the threshold, which should be set along the beam number as shown in Table 3. Note that Table 3 covers all the beams of ALOS-2 that are used for flood observation in Japan, but other satellites with different frequencies, $\mathrm{S} / \mathrm{N}$ ratios, and resolutions require different thresholds. The repeatability of the method was confirmed by various ALOS-2 datasets in this study, but the robustness of more complex models, such as machine learning, should be verified in the future using similar datasets.

Table 5. Summary of the advantages and disadvantages of the proposed method in terms of flood detection using ALOS-2 data.

\begin{tabular}{cccc}
\hline Method & Accuracy & Computation Speed & Repeatability \\
\hline $\begin{array}{c}\text { Conventional Method } \\
\text { (Simple Thresholding) }\end{array}$ & Low & Very High & High \\
\hline $\begin{array}{c}\text { Proposed Method } \\
\text { (Simple Probabilistic Model } \\
\text { Using SAR and Simulation) }\end{array}$ & High & High & High \\
\hline $\begin{array}{c}\text { Complex Method } \\
\text { (e.g., Machine Learning) }\end{array}$ & Very high & Low & Not proven \\
\hline User Requirement & High $(>60 \%)$ & High $(<30 \mathrm{~min})$ & High \\
\hline
\end{tabular}

\subsection{Operability of Flood Observation}

Based on the above results, we discuss the feasibility of daily flood monitoring using ALOS-2. Our results showed that ALOS-2 data observed in 3-m resolution Stripmap mode up to beam 14 (a $48.0^{\circ}$ off-nadir angle) can detect flood areas with acceptable accuracy. Figure 8 and Table 6 show that the use of beams up to 14 are sufficient for our primary purpose, i.e., daily flood monitoring. The ALOS-2 orbits the Earth 207 times (labelled path 1 to 207) in 14 days. For the flood in Joso $\left(36.0^{\circ} \mathrm{N}\right.$, $140.0^{\circ} \mathrm{E}$ ), for instance, the use of beams $2,5,8,11$, and 14 enables daily observation (details are shown in Table 6). For example, at noon (in a descending path) on day 1 , the satellites fly southward over path 19 (the thick red line in Figure 8a) and can observe the flood area by beam 5 in right-looking. 
The same area can also be observed again at midnight (in ascending orbit) from path 117 by beam 14 in left-looking. In total, two observations can be made on day 1.

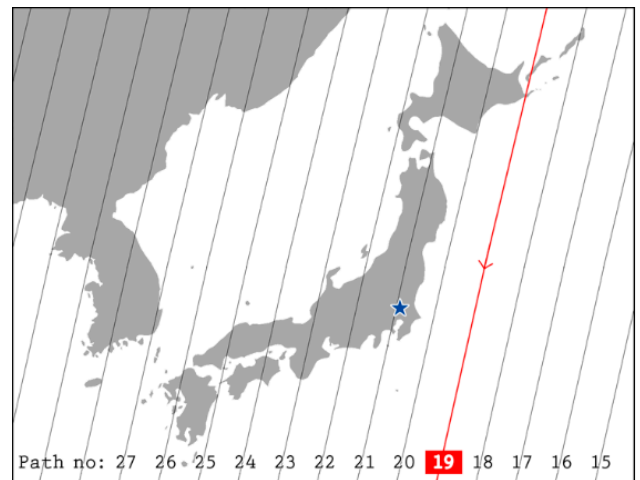

(a)

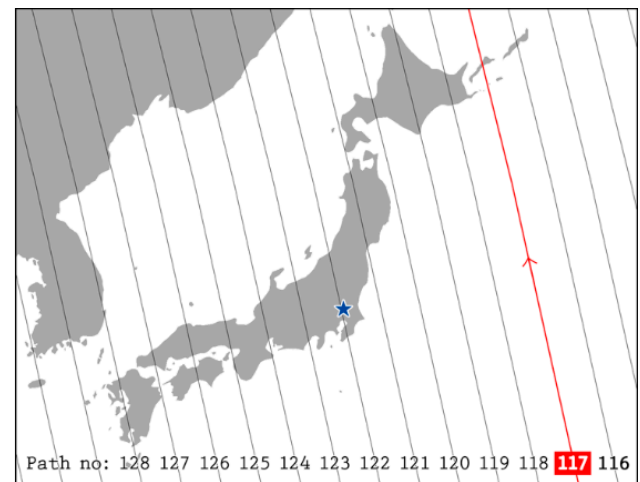

(b)

Figure 8. Orbital paths of ALOS-2: (a) descending and (b) ascending. Blue stars represent the affected area of the 2015 Joso flood $\left(36.0^{\circ} \mathrm{N}, 140.0^{\circ} \mathrm{E}\right)$ in Japan.

Table 6. Observation opportunities of ALOS-2 for the Joso area, Japan, in descending (D) and ascending (A) paths.

\begin{tabular}{|c|c|c|c|c|c|c|c|c|c|c|c|c|c|c|c|}
\hline \multicolumn{2}{|c|}{ Day No. } & 1 & 2 & 3 & 4 & 5 & 6 & 7 & 8 & 9 & 10 & 11 & 12 & 13 & 14 \\
\hline \multirow{2}{*}{ Descending } & Path Number & 19 & 22 & 25 & (14) & 17 & 20 & 23 & 26 & (15) & 18 & $(21)$ & 24 & $(27)$ & 16 \\
\hline & Beam Number * & $5 R$ & $2 \mathrm{~L}$ & $11 \mathrm{~L}$ & (20R) & $11 R$ & $2 \mathrm{R}$ & $5 \mathrm{~L}$ & $14 \mathrm{~L}$ & $(17 R)$ & $8 R$ & $(N / A)$ & $8 \mathrm{~L}$ & $(17 L)$ & $14 \mathrm{R}$ \\
\hline \multirow{2}{*}{ Ascending } & Pass Number & 117 & 120 & 123 & 126 & (115) & 118 & 121 & 124 & 127 & (116) & 119 & $(122)$ & 125 & $(128)$ \\
\hline & Beam Number * & $14 \mathrm{~L}$ & $5 \mathrm{~L}$ & $2 \mathrm{R}$ & $11 \mathrm{R}$ & $(20 L)$ & $11 \mathrm{~L}$ & $2 \mathrm{~L}$ & $5 R$ & $14 \mathrm{R}$ & $(17 L)$ & $8 \mathrm{~L}$ & $(N / A)$ & $8 \mathrm{R}$ & (18R) \\
\hline \multicolumn{2}{|c|}{$\begin{array}{c}\text { Total Number of Observations } \\
\text { Using Beam } \leq 14\end{array}$} & 2 & 2 & 2 & 1 & 1 & 2 & 2 & 2 & 1 & 1 & 1 & 1 & 1 & 1 \\
\hline
\end{tabular}

* L: Left-looking, R: Right-looking, N/A: not observable because the target area is on the nadir direction.

The ALOS-4, the follow-on satellite capable of similar observation and with an extended swath width is scheduled to be launched in the same orbital plane and operated simultaneously with ALOS-2. Table 7 shows the number of observations on each half-day by comparing three configurations, i.e., ALOS-2 only, ALOS-2 and -4 with $180^{\circ}$ of orbit separation, and ALOS-2 and -4 with $103^{\circ}$ separation. In the case of the $180^{\circ}$ separation, ALOS-4 will follow the same observation paths seven days after ALOS-2 but observation gaps will remain (the number of observations is zero in Table 7) at noon on days 2 and 9, and at midnight on days and 3 and 10. Based on the orbital theory, there are 14 possible angles $\left(\mathrm{n} / 14 \times 360^{\circ}\right)$ of separation in the orbital plane and $103^{\circ}(\mathrm{n}=4)$, in which ALOS-4 will follow the same observation paths after six days, enabling gapless twice-daily observation. Therefore, this study recommends $103^{\circ}$ of separation between the two satellites for rapid and frequent disaster monitoring.

Table 7. The number of observation opportunities using beams 1 to 14 of ALOS-2 for the Joso area, Japan, comparing three satellite configurations: ALOS-2 only, ALOS-2 and 4 with $180^{\circ}$ of separation, ALOS-2 and 4 with $103^{\circ}$ of separation.

\begin{tabular}{|c|c|c|c|c|c|c|c|c|c|c|c|c|c|c|c|}
\hline & Day No. & 1 & 2 & 3 & 4 & 5 & 6 & 7 & 8 & 9 & 10 & 11 & 12 & 13 & 14 \\
\hline \multirow{2}{*}{ Only ALOS-2 } & Descending & 1 & 1 & 1 & 0 & 1 & 1 & 1 & 1 & 0 & 1 & 0 & 1 & 0 & 1 \\
\hline & Ascending & 1 & 1 & 1 & 1 & 0 & 1 & 1 & 1 & 1 & 0 & 1 & 0 & 1 & 0 \\
\hline \multirow{2}{*}{$\begin{array}{l}\text { ALOS-2 and } 4 \\
\text { (180 deg) }\end{array}$} & Descending & 2 & 0 & 2 & 1 & 2 & 2 & 1 & 2 & 0 & 2 & 1 & 2 & 2 & 1 \\
\hline & Ascending & 1 & 2 & 0 & 2 & 1 & 2 & 2 & 1 & 2 & 0 & 2 & 1 & 2 & 2 \\
\hline \multirow{2}{*}{$\begin{array}{l}\text { ALOS-2 and } 4 \\
\text { (103 deg) }\end{array}$} & Descending & 2 & 1 & 1 & 1 & 2 & 2 & 2 & 1 & 1 & 1 & 2 & 1 & 2 & 1 \\
\hline & Ascending & 1 & 2 & 1 & 1 & 1 & 2 & 2 & 2 & 1 & 1 & 1 & 2 & 1 & 2 \\
\hline
\end{tabular}

* L: Left-looking, R: Right-looking, N/A: not observable because the target area is on the nadir direction. 
The complementary use of other SAR satellites should also be considered in the future. As an example, the European Sentinel-1 mission can observe any location at six-day intervals using two satellites. As these satellites have different radar frequencies, $\mathrm{S} / \mathrm{N}$ ratios, and scattering characteristics, it is necessary to modify their thresholds.

\section{Conclusions}

In this study, we developed a fully automatic, fast computation, and robust method for detecting flood areas using two complementary data types: SAR data from ALOS-2 and hydrodynamic flood simulation data by TE. We adopted Bayesian inference to combine the SAR amplitude/coherence and simulated flood fraction data. From the experimental results obtained by 12 datasets (corresponding to seven flood events) for urban-area flooding in Japan, the following conclusions were reached.

1. The simulated flood fraction data contributed to improving flood detection results at an accuracy higher than in previous studies. One should note that the accuracy depended on the observation conditions, i.e., appropriate off-nadir angles $\left(<50^{\circ}\right.$ for acceptable accuracy) and the availability of sufficient time-series pre-event data.

2. Flood fraction also effectively reduced computation time by skipping unnecessary processing for non-flooded areas and fulfilled user requirements (processing within two hours).

3. Our method proved robust against non-ideal observation conditions, e.g., data with large off-nadir angles, different off-nadir angles or observation modes between co- and pre-event data, and long temporal intervals among time-series data.

4. The robustness of our method and the observation capability of ALOS-2 satellite enable daily flood monitoring. If ALOS-4 is also used, the satellites can provide twice-daily monitoring.

In summary, our method using ALOS-2 and TE can effectively monitor urban-area flooding and can be transferred to operational use.

For simplicity and fast computation, the present method assumed simple Bayesian inference, simple Gaussian probability density functions, and a limited number of random variables. More complex models and more random variables are expected to further improve accuracy. For example, the use of more time-series SAR amplitude/coherence data and consideration of amplitude increases by the double-bounce effect were not included. The present study focused on urban floods in areas in Japan, but future work should also consider floods in other areas. It is required to add the category $\mathrm{F}_{5}$ (flooded vegetation), which was ignored in the present study. The limited resolution of the flood simulation, particularly outside of Japan $(25 \mathrm{~km})$, should be improved for better estimation of floods. Furthermore, this study only addressed the use of ALOS-2; the inclusion of other SAR satellites should be considered.

Hydrodynamic simulation data with a high temporal frequency and SAR data with high spatial resolution can have complementary roles in flood monitoring. Although this study showed how simulation can improve SAR analysis, the extent to which SAR could improve the resolution and accuracy of the model should also be studied.

Author Contributions: Conceptualization, validation, and original draft preparation, M.O.; methodology, M.O., and K.Y. (Kosuke Yamamoto); review and editing, T.T., K.Y. (Kosuke Yamamoto), and K.Y. (Kei Yoshimura); project administration, T.T; supervision, K.Y. (Kei Yoshimura). All authors have read and agreed to the published version of the manuscript.

Funding: This research received no external funding.

Acknowledgments: The authors would like to thank Ryo Natsuaki for his helpful suggestions on interferometric analysis.

Conflicts of Interest: The authors declare no conflict of interest. 


\section{Appendix A}

Appendix A describes our method and the benefit of its use of histogram matching for coherence images in pre-processing (Section 3.1). In case 2 of this study, for instance, the co-event coherence highly decorrelated (Figure A1b) because of the long temporal distance compared to the pre-event coherence (Figure A1a), resulting in large negative values in the difference in coherence (Figure A1c). Histogram matching is the process of modifying the pixel values so that the image histogram is equalized to another image histogram. In this study, the histogram of co-event coherence is equalized to that of pre-event coherence. The use of standard histogram matching resulted in low-coherence areas due to floods that are too much higher to fit forcibly to the pre-event histogram; this resulted in large positive values in coherence difference (Figure A1d).

We propose masked histogram matching that uses only the histograms where FLDFRC $_{\max }$ is very small $(<0.05)$ to avoid erroneous matching in flood areas. The matched co-event coherence was obtained by applying the matching table to the entire image. The differential coherence image obtained from the matched co-event coherence adequately showed the decrease in coherence in flooded objects (Figure A1e).

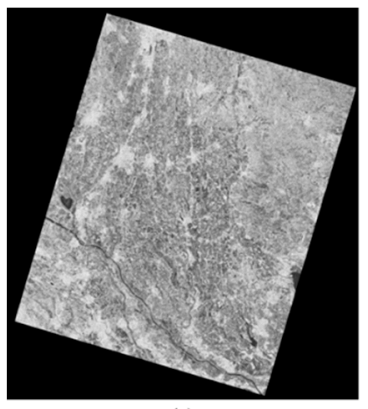

(a)

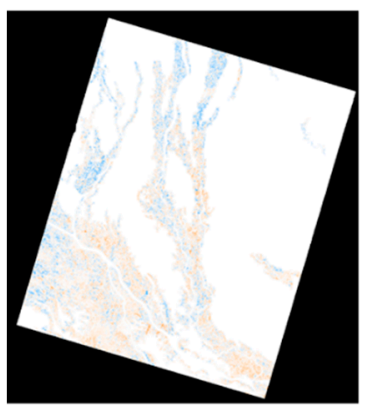

(d)

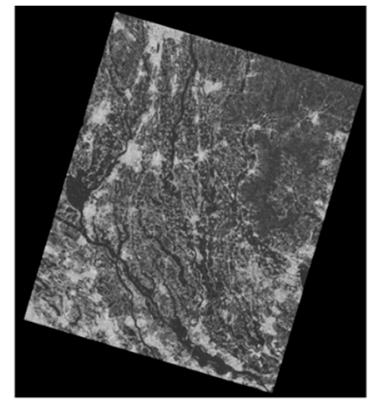

(b)

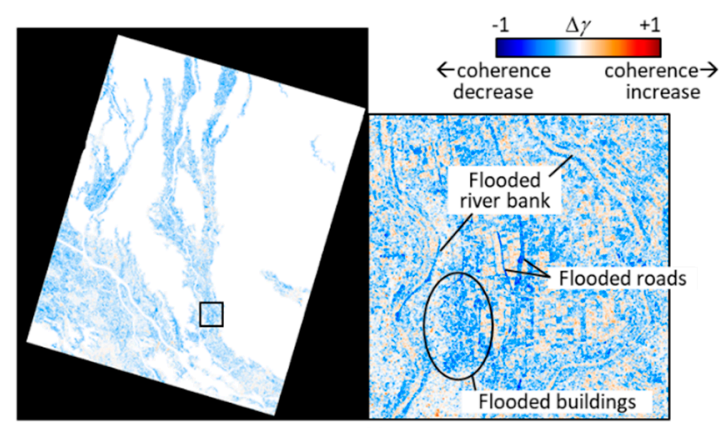

(e)

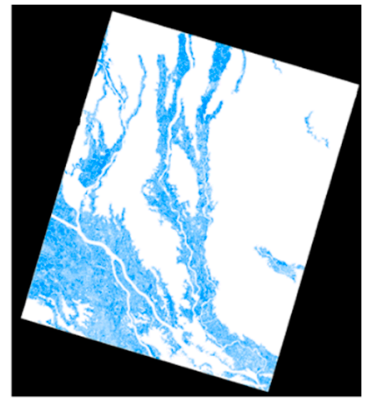

(c) 
in the grid. In our experience, if FLDFRC $\max >0.3$, there is enough possibility to classify the area as flooded (f $\sim 0.5)$.

For these reasons, instead of using $\mathrm{FLDFRC}_{\max }$ itself as a prior probability, we introduced the logistic function shown in Equation (3). Based on the requirements described above, $A$ controls the maximum value of $f$ and is set to $0.5,1 / B$ (the sharpness of the rising edge of $f$ ) is 0.05 , and $C$ (the position of rising edge) is 0.2 in Equation (3). Thus, $f$ reaches its maximum value (0.5) around FLDFRC $_{\max }=0.3$ as shown in Figure A2.

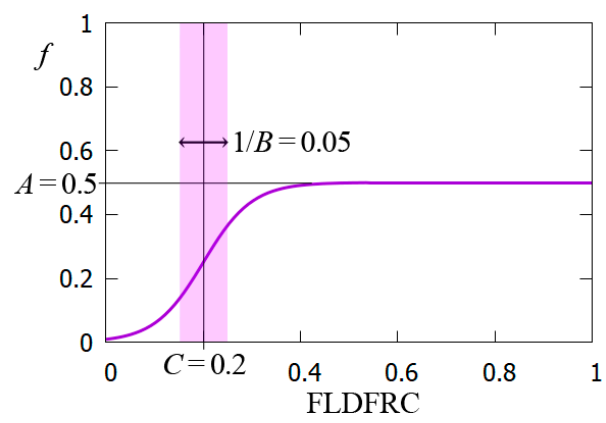

Figure A2. Flood prior probability $f$ versus FLDFRC $_{\max }$.

\section{References}

1. International Federation of Red Cross and Red Crescent Societies. World Disasters Rep; IFRC: Geneva, Switzerland, 2016.

2. Van Alphen, J.; Bourger, L.; Elliott, C.; Fujita, K.I.; Riedstra, D.; Rooke, D.; Tachi, K. Flood Risk Management Approaches: As Being Practiced in Japan, Netherlands, United Kingdom and United States; IWR Report 2011-R-08; USACE: Washington, DC, USA; Rijkswaterstaat: Vlissingen, The Netherlands; MLIT: Tokyo, Japan; Environment Agency: Bristol, UK, 2011.

3. Intergovernmental Panel on Climate Change. Summary for Policymakers. In Climate Change 2014; Cambridge University Press: Cambridge, UK; New York, NY, USA, 2014.

4. Rango, A.; Salomonson, V.V. Regional flood mapping from space. Water Resour. Res. 1974, 10, 473-484. [CrossRef]

5. Okada, Y.; Nakamura, S.; Iribe, K.; Yokota, Y.; Tsuji, M.; Tsuchida, M.; Hariu, K.; Kankaku, Y.; Suzuki, S.; Osawa, Y. System Design of Wide Swath, High Resolution, Full Polarimietoric L-Band SAR Onboard ALOS-2. In Proceedings of the 2013 IEEE International Geoscience and Remote Sensing Symposium, Melbourne, Australia, 21-26 July 2013; pp. 2408-2411.

6. Smith, L.C. Satellite Remote Sensing of River Inundation Area, Stage, and Discharge: A Review. Hydrol. Process. 1997, 11, 1427-1439. [CrossRef]

7. Mason, D.; Speck, R.; Devereux, B.; Schumann, G.J.-P.; Neal, J.C.; Bates, P. Flood Detection in Urban Areas Using TerraSAR-X. IEEE Trans. Geosci. Remote Sens. 2009, 48, 882-894. [CrossRef]

8. Giustarini, L.; Hostache, R.; Matgen, P.; Bates, P.; Mason, D.C.; Schumann, G.J.-P. A Change Detection Approach to Flood Mapping in Urban Areas Using TerraSAR-X. IEEE Trans. Geosci. Remote Sens. 2012, 51, 2417-2430. [CrossRef]

9. Shen, X.; Wang, D.; Mao, K.; Anagnostou, E.; Hong, Y. Inundation Extent Mapping by Synthetic Aperture Radar: A Review. Remote Sens. 2019, 11, 879. [CrossRef]

10. Ohki, M.; Tadono, T.; Itoh, T.; Ishii, K.; Yamanokuchi, T.; Watanabe, M.; Shimada, M. Flood Area Detection Using PALSAR-2 Amplitude and Coherence Data: The Case of the 2015 Heavy Rainfall in Japan. IEEE J. Sel. Top. Appl. Earth Obs. Remote Sens. 2019, 12, 2288-2298. [CrossRef]

11. Mason, D.; Giustarini, L.; García-Pintado, J.; Cloke, H. Detection of flooded urban areas in high resolution Synthetic Aperture Radar images using double scattering. Int. J. Appl. Earth Obs. Geoinf. 2014, 28, 150-159. [CrossRef]

12. Arii, M. Sensitivity Study of ALOS-2 Data to Floodwaters in Joso City in 2015 and its Application. J. Remote Sens. Soc. Jpn. 2018, 38, 325-336.

13. Refice, A.; Capolongo, D.; Pasquariello, G.; DaAddabbo, A.; Bovenga, F.; Nutricato, R.; Lovergine, F.P.; Pietranera, L.; D'Addabbo, A. SAR and InSAR for Flood Monitoring: Examples With COSMO-SkyMed Data. IEEE J. Sel. Top. Appl. Earth Obs. Remote Sens. 2014, 7, 2711-2722. [CrossRef] 
14. Pulvirenti, L.; Chini, M.; Pierdicca, N.; Boni, G. Use of SAR Data for Detecting Floodwater in Urban and Agricultural Areas: The Role of the Interferometric Coherence. IEEE Trans. Geosci. Remote Sens. 2015, 54, 1532-1544. [CrossRef]

15. Chini, M.; Pelich, R.; Pulvirenti, L.; Pierdicca, N.; Hostache, R.; Matgen, P. Sentinel-1 InSAR Coherence to Detect Floodwater in Urban Areas: Houston and Hurricane Harvey as A Test Case. Remote Sens. 2019, 11, 107. [CrossRef]

16. Ormsby, J.P.; Blanchard, B.J.; Blanchard, A.J. Detection of lowland flooding using active microwave systems. Photogramm. Eng. Remote Sens. 1985, 51, 317-328.

17. Imhoff, M.L.; McCandless, S. Flood boundary delineation through clouds and vegetation using l-band space-borne radar: A potential new tool for disease vector control programs. Acta Astronaut. 1988, 17, 1003-1007. [CrossRef]

18. Martinis, S.; Twele, A.; Voigt, S. Towards operational near real-time flood detection using a split-based automatic thresholding procedure on high resolution TerraSAR-X data. Nat. Hazards Earth Syst. Sci. 2009, 9, 303-314. [CrossRef]

19. Chini, M.; Hostache, R.; Giustarini, L.; Matgen, P. A Hierarchical Split-Based Approach for Parametric Thresholding of SAR Images: Flood Inundation as a Test Case. IEEE Trans. Geosci. Remote Sens. 2017, 55, 6975-6988. [CrossRef]

20. Pulvirenti, L.; Chini, M.; Pierdicca, N.; Guerriero, L.; Ferrazzoli, P. Flood monitoring using multi-temporal COSMO-SkyMed data: Image segmentation and signature interpretation. Remote Sens. Environ. 2011, 115, 990-1002. [CrossRef]

21. Kang, W.; Xiang, Y.; Wang, F.; Wan, L.; You, H. Flood Detection in Gaofen-3 SAR Images via Fully Convolutional Networks. Sensors 2018, 18, 2915. [CrossRef]

22. Li, Y.; Martinis, S.; Wieland, M. Urban flood mapping with an active self-learning convolutional neural network based on TerraSAR-X intensity and interferometric coherence. ISPRS J. Photogramm. Remote Sens. 2019, 152, 178-191. [CrossRef]

23. Shen, X.; Anagnostou, E.N.; Allen, G.H.; Brakenridge, G.R.; Kettner, A.J. Near-real-time non-obstructed flood inundation mapping using synthetic aperture radar. Remote Sens. Environ. 2019, 221, 302-315. [CrossRef]

24. Martinis, S.; Kersten, J.; Twele, A. A fully automated TerraSAR-X based flood service. ISPRS J. Photogramm. Remote Sens. 2015, 104, 203-212. [CrossRef]

25. Twele, A.; Cao, W.; Plank, S.; Martinis, S. Sentinel-1-based flood mapping: A fully automated processing chain. Int. J. Remote Sens. 2016, 37, 2990-3004. [CrossRef]

26. Cabinet Office, Government of Japan. Enhancement of National Resilience against Natural Disasters. In SIP-Pioneering the Future: Japanese Science, Technology and Innovation 2019; Cabinet Office: Tokyo, Japan, 2019; pp. 66-67.

27. Japan Aerospace Exploration Agency. Available online: https://www.eorc.jaxa.jp/water/ (accessed on 1 June 2020).

28. Yoshimura, K.; Sakimura, T.; Oki, T.; Kanae, S.; Seto, S. Toward flood risk prediction: A statistical approach using a 29-year river discharge simulation over Japan. Hydrol. Res. Lett. 2008, 2, 22-26. [CrossRef]

29. Yoshimura, K.; Ishitsuka, Y.; Hibino, K.; Yamazaki, D.; Yamamoto, K.; Kachi, M.; Oki, R. Development of Flood Forecasting System over Japan and Application to 2018 Japan Floods Event. In EGU2019, Geophysical Research Abstracts; EBSCO Industries, Inc.: Birmingham, AL, USA, 2019.

30. D'Addabbo, A.; Refice, A.; Pasquariello, G.; Lovergine, F.P.; Capolongo, D.; Manfreda, S. A Bayesian Network for Flood Detection Combining SAR Imagery and Ancillary Data. IEEE Trans. Geosci. Remote Sens. 2016, 54, 3612-3625. [CrossRef]

31. Giustarini, L.; Hostache, R.; Kavetski, D.; Chini, M.; Corato, G.; Schlaffer, S.; Matgen, P. Probabilistic Flood Mapping Using Synthetic Aperture Radar Data. IEEE Trans. Geosci. Remote Sens. 2016, 54, 6958-6969. [CrossRef]

32. Geospatial Information Authority of Japan. Information on 2015 Kanto-Tohoku Heavy Rainfall. Available online: https://www.gsi.go.jp/BOUSAI/H27.taihuu18gou.html (accessed on 1 June 2020).

33. Geospatial Information Authority of Japan. Information on Typhoon 11 and 9 of 2016. Available online: https://www.gsi.go.jp/BOUSAI/H28.taihuu11_9gou.html (accessed on 1 June 2020).

34. Geospatial Information Authority of Japan. Information on July 2018 Heavy Rainfall. Available online: https://www.gsi.go.jp/BOUSAI/H30.taihuu7gou.html (accessed on 1 June 2020).

35. Geospatial Information Authority of Japan. Information on August 2019 Heavy Rainfall. Available online: https://www.gsi.go.jp/BOUSAI/R1_kyusyu_heavyrain.html (accessed on 1 June 2020). 
36. Geospatial Information Authority of Japan. Information on Eastern Japan Typhoons in 2019. Available online: https://www.gsi.go.jp/BOUSAI/R1.taihuu19gou.html (accessed on 1 June 2020).

37. Geospatial Information Authority of Japan. Information on October 2019 Heavy Rainfall. Available online: https://www.gsi.go.jp/BOUSAI/R1_10gatsuheavyrain.html (accessed on 1 June 2020).

38. Takata, K.; Emori, S.; Watanabe, T. Development of the minimal advanced treatments of surface interaction and runoff. Glob. Planet. Chang. 2003, 38, 209-222. [CrossRef]

39. Nitta, T.; Yoshimura, K.; Takata, K.; O’Ishi, R.; Sueyoshi, T.; Kanae, S.; Oki, T.; Abe-Ouchi, A.; Liston, G.E. Representing Variability in Subgrid Snow Cover and Snow Depth in a Global Land Model: Offline Validation. J. Clim. 2014, 27, 3318-3330. [CrossRef]

40. Yamazaki, D.; Kanae, S.; Kim, H.; Oki, T. A physically based description of floodplain inundation dynamics in a global river routing model. Water Resour. Res. 2011, 47. [CrossRef]

41. Yamazaki, D.; De Almeida, G.A.M.; Bates, P. Improving computational efficiency in global river models by implementing the local inertial flow equation and a vector-based river network map: Speeding Up Global River Model Simulations. Water Resour. Res. 2013, 49, 7221-7235. [CrossRef]

42. Bates, P.; Horritt, M.S.; Fewtrell, T.J. A simple inertial formulation of the shallow water equations for efficient two-dimensional flood inundation modelling. J. Hydrol. 2010, 387, 33-45. [CrossRef]

43. Shi, Z.; Fung, K.B. A Comparison of Digital Speckle Filters. In Proceedings of the 1994 IEEE International Geoscience and Remote Sensing Symposium, Pasadena, CA, USA, 8-12 August 1994; Volume 4, pp. 2129-2133.

44. Ohki, M.; Shimada, M. Flood-Area Detection Using Palsar-2 Data for Heavy Rainfall Disasters in Japan. In Proceedings of the IGARSS 2018-2018 IEEE International Geoscience and Remote Sensing Symposium, Valencia, Spain, 22-27 July 2018; pp. 8777-8780. [CrossRef]

45. Zebker, H.; Villasenor, J. Decorrelation in interferometric radar echoes. IEEE Trans. Geosci. Remote Sens. 1992, 30, 950-959. [CrossRef]

46. Fung, A.K.; Chen, K.S. Dependence of the surface backscattering coefficients on roughness, frequency and polarization states. Int. J. Remote Sens. 1992, 13, 1663-1680. [CrossRef]

47. Douglas, D.H.; Peucker, T.K. Algorithms for the Reduction of the Number of Points Required to Represent a Digitized Line or Its Caricature. In Classics in Cartography; Dodge, M., Ed.; John Wiley \& Sons, Ltd.: Chichester, UK, 2011; pp. 15-28.

48. Congalton, R.G. A review of assessing the accuracy of classifications of remotely sensed data. Remote Sens. Environ. 1991, 37, 35-46. [CrossRef]

49. Natsuaki, R.; Nagai, H. Synthetic Aperture Radar Flood Detection under Multiple Modes and Multiple Orbit Conditions: A Case Study in Japan on Typhoon Hagibis, 2019. Remote Sens. 2020, 12, 903. [CrossRef]

50. Okada, Y.; Yokota, Y.; Karasawa, A.; Matsuki, M.; Arii, M.; Nakamura, S. Hardware Performance of PALSAR-3 Onboard ALOS-4. In Proceedings of the IGARSS 2018-2018 IEEE International Geoscience and Remote Sensing Symposium, Valencia, Spain, 22-27 July 2018; pp. 4175-4176. [CrossRef]

51. Rimba, A.B.; Miura, F. Evaluating the Extraction Approaches of Flood Extended Area by Using ALOS-2/ PALSAR-2 Images as a Rapid Response to Flood Disaster. J. Geosci. Environ. Prot. 2017, 5, 40-61. [CrossRef]

52. Liu, W.; Yamazaki, F. Review article: Detection of inundation areas due to the 2015 Kanto and Tohoku torrential rain in Japan based on multi-temporal ALOS-2 imagery. Nat. Hazards Earth Syst. Sci. 2018, 18, 1905-1918. [CrossRef]

53. Li, Y.; Martinis, S.; Wieland, M.; Schlaffer, S.; Natsuaki, R. Urban Flood Mapping Using SAR Intensity and Interferometric Coherence via Bayesian Network Fusion. Remote Sens. 2019, 11, 2231. [CrossRef]

54. Ohki, M.; Tadono, T.; Itoh, T.; Ishii, K.; Yamanokuchi, T.; Shimada, M. Flood Detection in Built-Up Areas Using Interferometric Phase Statistics of PALSAR-2 Data. IEEE Geosci. Remote Sens. Lett. 2020, 1-5. [CrossRef]

55. Liu, W.; Yamazaki, F.; Maruyama, Y. Extraction of Inundation Areas Due to the July 2018 Western Japan Torrential Rain Event Using Multi-Temporal ALOS-2 Images. J. Disaster Res. 2019, 14, 445-455. [CrossRef]

(C) 2020 by the authors. Licensee MDPI, Basel, Switzerland. This article is an open access article distributed under the terms and conditions of the Creative Commons Attribution (CC BY) license (http://creativecommons.org/licenses/by/4.0/). 